\title{
Contemporary Social Work Practice: The struggles of transforming yesterday's professional skill set
}

\section{Barbara Neale}

A thesis submitted to The University of Gloucestershire in accordance with the requirements of the degree of Masters by Research in the School of Health and Social Care

February 2020

Word Count: 31,141 


\section{Abstract}

Social work is a practice-based profession that is underpinned by the principles of social justice and the promotion of empowerment. It has two key aims; to enhance the wellbeing of vulnerable people through the application of relationship-based practice and to carry out the government commissioned safeguarding duties of local authorities that are informed by law. In order to meet these dual aims, social workers need to apply a body of knowledge, skills and qualities to their work that will enable them to meet the diverse needs of vulnerable people living within the local authority urban and rural communities.

Within this study, I argue that the knowledge, skills and qualities have become compromised and this has subsequently impacted on the social work profession. I consider the tensions that have arisen between the values and duties of the social work profession and successive government agendas since the 1970s, in respect to the standards and expectations of statutory social work practice. These tensions relate to both the substantial cuts to the funding of the services in which the social work profession is expected to carry out its duties and responsibilities and qualifying and practicing social workers being deemed as "ill-equipped" with the necessary knowledge, skills and qualities to carry out their statutory duties.

I argue that the sequence of government interventions and the findings within more recent serious case reviews such as the tragic loss of life of Victoria Climbie (2000) have failed to consider the political regime in which social work is practiced. I consider, that as a consequence of this, relationship-based practice has been compromised in favour of a government-led administrative processes as a result of a growing culture of fear and blaming social workers for failings in practice. I argue that social workers are victims of "epistemic injustice", a concept of prejudicial injustice that rises against someone in their capacity as a knower. Through the application of qualitative methodology, I will draw on the voices of 12 social workers from a range of qualifying pathways in order to explore how social workers themselves understand these tensions and what knowledge, skills and qualities they consider are critical to carryout out contemporary statutory social work practice. 


\section{Declaration}

I declare that the work in this thesis was carried out in accordance with the regulations of the University of Gloucestershire and is original except where indicated by specific reference in the text. No part of the thesis has been submitted as part of any other academic award. The thesis has not been presented to any other education institution in the United Kingdom or overseas.

Any views expressed in the thesis are those of the author and in no way represent those of the University.

Signed

Date ......07-08-2019 


\section{Acknowledgements}

I would like to thank my supervisor Alex Masardo. I am extremely fortunate to have been supported by Alex to complete this study. Alex has shared his knowledge and provided guidance, care and support which has been nothing less than extraordinary. I am so thankful to Alex who has kept me structured and has encouraged me to think and learn beyond what I considered my own capacity.

I would like to make a personal tribute to Katy Burton, the Course Administrator for the Masters in Research programme. I consider Katy to be the cornerstone for this programme. Katy is consistent with her support, guidance, kindness and outstanding professionalism in response to my every query, for which there were many. The university is fortunate to have her working for them and it would be a very sad place without her.

I am surrounded by a wonderful family, great friends and supportive colleagues. Thank you all so much. There are no words to express my gratitude and how much your encouragement has meant to me.

To my two beautiful children Rhiannon and Rhydian, for whom I am immensely proud. At the time of completing this study you have both faced your own life experiences of; beginning and ending your degrees and conquering the challenge of exams, dissertations, leaving home, starting your careers and learning to live independent lives. I am so grateful for your love, respect, kindness and support that you give to me.

Finally, my wonderful husband and best friend Malcolm who is the most kind, caring and stable person I know. Thank you Malc, irrespective of all the challenges endured I am forever blessed and thankful for your love, patience, kindness and support. 
Title Page

Abstract

Declaration

Acknowledgements

Contents

\section{Chapter 1 - Introduction}

1.1 The International Federation of Social Workers (IFSW).

8

1.2 Statutory social work

1.3 Social work education.

1.4 Government Interventions

1.5 Austerity, neo-liberalism and the social work profession

1.6 Epistemic Injustice; a new theoretical lens for social work practice..

1.7 Methodology

1.8 Research ethics

1.9 Study aims

\section{Chapter 2 - The Regulatory Framework for Social Work and BASW}

2.1 Local authorities and social work

2.2 British association of social work (BASW)

2.3 The regulatory body for social work

2.4 The general social care council (GSCC)

2.5 The social work task force (2009)

2.6 The college of social work

2.7 The health care professional council (2012)

2.8 The knowledge and skill statement.

2.9 Social work England

\section{Chapter 3}

\section{Literature Review - Public and Social Discourse}

3.1 Victoria Climbie

3.2 Baby Peter

3.3 Lord Laming report (2009)

3.4 The Munro report (2011) ..................................................... $29-32$

3.5 Professor David Croisdale-Appleby review (2014) ........................ 32 - 34

3.6 Sir Martin Narey - Independent report (2014)

3.7 Discussions

3.7.1 Public and social discourse

$35-36$

3.7.2 Relationship based practice - Statutory practice

3.7.3 Epistemic and hermeneutical Injustice

3.7.4 Educational routes of entrance into social work - the professional skill set 


\section{Chapter 4}

Routes of Entrance into the Social work Profession

4.1 Introduction ......................................................................... 40 - 41

4.2 Higher education Institution (HEl's) - Generic social work education . 41 - 43

4.3 New routes of entrance into social work ......................................... 43 - 44

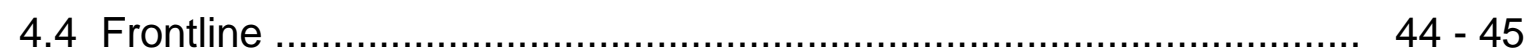

4.5 Step Up to social work ....................................................... 45 - 46

4.6 Think Ahead - Mental health ................................................... 46

4.7 The apprenticeship route ........................................................ 46 - 47

4.8 Discussions

4.8.1 Epistemological position …………………………..... 47 - 48

4.8.2 Quality versus quantity ............................................. 48 - 49

4.8.3 Regulations ............................................................ $49-50$

4.8.4 Education and epistemic injustice ................................. 50 - 51

4.8.5 Generic practice and specialise practice .......................... $51-53$

4.8.6 Practice based learning (PBL) ………………............... $53-54$

\section{Chapter 5 - Methodology}

5.1 The Aim of primary, qualitative research ...................................... 55

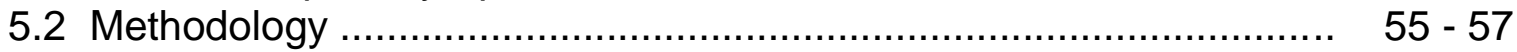

5.3 Purposive sampling …….................................................. 57 - 58

5.4 Professional research ethics ................................................ 58- 59

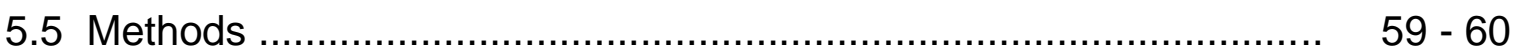

5.6 Participation ........................................................................ 60 - 61

5.7 Pilot Interviews ................................................................ $61-65$

5.7.1 Stage One - Openings - Welcome and agreements ............. 62

5.7.2 Stage Two - Introductory stage - Demographic exploration. 62

5.7.3 Stage Three- Transitions - The ASYE - Learning and experiences .................................................. 63

5.7.4 Stage Four - Key Stage - The professional skill set ........... 63

5.7.5 Endings - Stage Five - Professional development and future plans

\section{Chapter 6}

Stage Two and Three - Data Analysis and Discussion

6.1 Data Analysis......................................................................... 65

6.2 Introductory Stage - Stage Two - Demographics ............................ 65

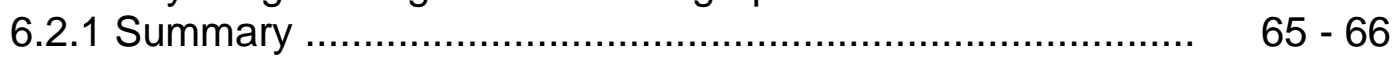

6.3 Stage Three - Transitions ………………………………... 66

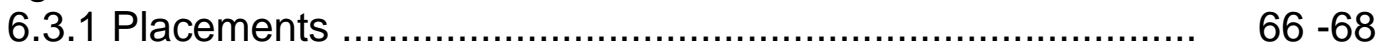

6.3.2 Leadership and management ...................................... $68-69$

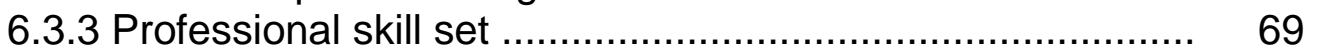

6.4 Discussion and conclusion ..................................................... $69-71$

\section{Chapter 7}

\section{Stage Four - Key Stage - Data Findings and Analysis}

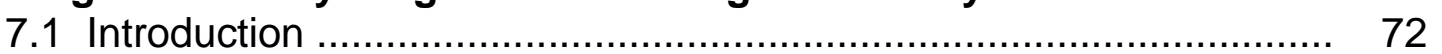

7.2 The professional skill set ................................................. 72 - 74

7.3 Theory versus practice based learning ………........................... $\quad 74-75$

7.4 Relationship-based practice and statutory duties ....................... $\quad 75-77$ 
7.5 Leadership and management ................................................. $\quad 77$

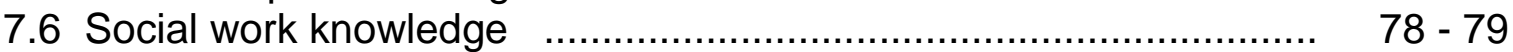

7.7 Social work skills ................................................................ 79 - 80

7.8 Social work qualities .......................................................... $80-81$

7.9 Epistemic Injustice and the distribution of power .......................... $81-83$

\section{Chapter 8 - Conclusion}

8.1 Introduction.................................................................... $84-85$

8.2 The tensions between the values and duties of the social work profession.

$85-86$

8.3 The regulatory body and non-regulator body: the professional skill set

86

8.4 Educational routes into the profession...................................... $86-87$

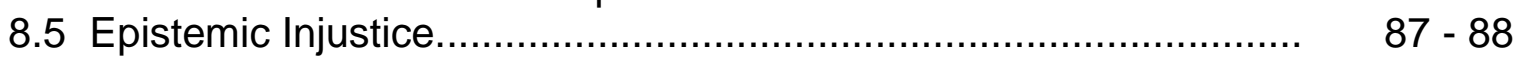

8.6 A future view for social work ……........................................... $88-89$

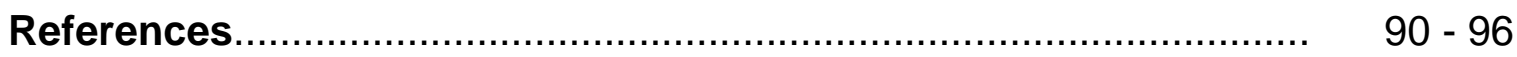

Appendices

Appendix One: Invitation to Participate ……………................... 97

Appendix Two: Consent and participation information sheet ............ $\quad 98$ - 99

Appendix Three: Debrief Form ........................................................ 100

Appendix Four: Semi-Structured Interview ................................. $101-102$

Appendix Five: Demography ……………………..................... $103-104$

Appendix Six: ASYE Themes .................................................. $105-106$

Appendix Seven: Professional Skill Set .......................................... $107-109$ 


\section{Chapter 1}

\section{Introduction}

\subsection{The Social Work profession - International Federation of Social Workers}

(IFSW)

The International Federation of Social Workers is the worldwide body for professional social work who set and review international standards for social work. The IFSW purpose is to contribute to achieving social justice across the world. The federation is representative of over 3 million social workers with its global definition of prompting the intention of good practice outcomes alongside its partners at national and/or regional levels.

"Social work is a practice-based profession and an academic discipline that promotes social change and development, social cohesion, and the empowerment and liberation of people. Principles of social justice, human rights, collective responsibility and respect for diversities are central to social work. Underpinned by theories of social work, social sciences, humanities and indigenous knowledge, social work engages people and structures to address life challenges and enhance wellbeing. ( IFSW \& the IASSW General Assembly in July 2014)

\subsection{Statutory social work}

Local authorities have a statutory responsibility to promote and protect the welfare and wellbeing of children, adults at risk within rural towns and communities. Their statutory powers are applied when very serious complex issues arise that could cause neglect, harm and risk of loss of life. In such circumstances, the importance of balancing relationship based practice, competing needs, risks and rights are critical to the allembracing decisions that are made for statutory interventions to be undertaken. Highly qualified professional social workers employed by local authorities are seen as holding a primary position as the skilled professional to advocate and exercise these functions.

A professionally qualified social worker must complete a professional training programme in order to register and practice as a social worker to work within both statutory and non-statutory roles. A social worker is required to develop and apply a collective body of skills and knowledge underpinned by the values of the social work profession that informs relationship based practice, variously described as being 'at the heart of social work' (Trevithick, 2003) and carryout statutory duties in social work. Characteristics in respect to relationship based practice refer to; human personality 
and functioning in terms of conscious and unconscious desires, beliefs, feelings and emotions, based on person's life experience: Equally an understanding of contextual factors such as power, a professional role, poverty, social exclusion and political ideology are seen as fundamental to the professional knowledge that informs the statutory and non-statutory driven task that social workers must also apply.

In a statutory position, social workers are required to carry out their duties within local authorities whose responsibility it is to work within the within the legal frameworks that exist such as, the Children and Families Act 2014 and the Care Act 2014. In nonstatutory roles, social workers work with vulnerable people but are not specifically responsible for enforcing the law. Non-statutory roles are held usually provided by voluntary and private organisations and provide critical support that aim to meet the identified needs of vulnerable people for whom they serve. For the purpose of this study, the main focus is placed on statutory social work and the phrase "social work profession" will be used as an all-encompassing term referring to, local authorities, qualifying and qualified social workers and social work Higher Education Institutions (HEl's).

Statutory social workers require a professional skill set that will enable them to contribute to completing a comprehensive assessment of the circumstances that are being experienced by vulnerable people and determine interventions such as; a protection plan or a care plan to help improve the individuals life; or safeguarding measures such as applying statutory procedures in order to prevent any further risk of harm to a vulnerable person. Social workers are expected to adopt a relationship based and multi disciplinary approach that requires working alongside other professional organisations such as; education, the police, health and private and voluntary care providing organisations: The multi disciplinary approach is intended to provide the relevant care and support that has been as assessed as needed to improve the life of a vulnerable person. The underlying expectation and principles of practice are informed by laws in which social workers practice. The multi professional approach enables the active development of a diverse range of professional opinions in order to manage risk and develop plans that work in the best interest and promote the wellbeing of the individual (Children and Families Directorate, 2010). 


\subsection{Social work education}

In order to become a professionally qualified social work practitioner and carry out the duties within statutory social work practice, it is a requirement to successfully complete a teaching programme that is validated by a regulating body for the profession. Since 2003, the main qualifications for social work in England have been a three year undergraduate Bachelor's degree (BA, BSc or BSW) in social work and a two year post qualifying Route Postgraduate Diploma in Social Work/ Masters (PgDip/ MSc). The teaching programmes are informed, developed and delivered in partnership with social work academics, senior social work staff, service users and carers who have been involved and supported by statutory services.

It is an expectation that educational routes into the profession, provide the relevant teaching, training and robust assessments that are required for social workers to demonstrate the professional skill set in order to qualify and practice. Social workers upon qualifying are expected to enter into practice, irrespective of whether they choose to enter into statutory or non-statutory professions with a professional skill set to carry out their duties and responsibilities within the profession. The foundations and evolution of new cost effective social work training routes arising within the profession and the learning outcome expectations for qualifying social workers are explored in further detail to inform the study.

\subsection{Government Interventions}

The recommendations of a public inquiry carried out by Lord Laming in 2001, and further reports and reviews that were carried out by Moira Gibb (2009), Professor Eileen Munro (2011), Professor David Croisdale-Appleby (2014) and Sir Martin Narey (2014) as a parliamentary response to poor practices leading to loss of life, have been enormously influential on the social work profession. The findings and recommendations that promoted change will be further examined within this study in respect to the: questioning of the knowledge, skills and qualities of the professional skill set for a qualifying social worker and their readiness to practice in statutory social work; educational route of entrance into the profession that is currently in favour of more specialised routes of entrance into the profession rather than a generic academic teaching programme. 


\subsection{Austerity, neo-Liberalism and the social work profession}

I am a senior lecturer and a registered qualified social work practitioner and have been in practice and involved in social work education over the course of 35 years. I hold a tremendous amount of experience and commitment to the field of social work practice, education and the value base of the social work profession. Since the 1980s, I have engaged in and witnessed fast flowing and significant changes within the social work profession. The changes refer to: rapidly growing, multi cultural society in which social workers are positioned to serve vulnerable people; the diminishing public funds that are provided by government to commission the local authorities to carry out their duties and responsibilities; the changes in applied practice of social workers that have become more conducive to a defensible and process driven application of practice that is compromising the values and possibilities of relationship-based practice.

Social work is positioned within a neo-liberalist political agenda, which is an ideology that has transformed the welfare state since the 1970s (Clarke, 2004). It is a policy model that aims to connect politics, social studies, and economics. The notion of a free-market and capitalism, is to move away from government spending, regulation, and public ownership by transferring the control of economic factors to the private sector from the public sector. It is referred to as a neo-liberal agenda that was seen to open up social services to the market and the private sector (Jones, 2015). The neoliberal model of purchasing and providing services within a localised market, was afforded at the time of austerity within the United Kingdom and has continued to impact on the social work profession.

The impact of austerity has reduced, a once generous budget that is required to meet the needs of growing and ever changing multi cultural communities and vulnerable people. However, there seems to be an absence of recognition and recommendations towards the responsibly of the government affording the service. I consider the lack of responsibility and provision of sufficient funding to provide the staff and resources to care and protect vulnerable people, is a major contributor to the reason why social workers are struggling to carry out their duties and responsibilities to care and safeguard the public. However, the findings and recommendations of the earlier mentioned government interventions have harshly criticised and blamed the social work profession for failing in their duties to protect vulnerable people. Therefore, I intend to examine the literature and identify if the commentators considered the 
government's position and responsibility to vulnerable people and the communities within the literature and the recommendations they made towards addressing those findings.

The commentaries within the literature of the findings and recommendations by the aforementioned leaders, have been enormously influential in regard to forming and influencing a negative view of the social work profession. It is my view that the social work profession is carrying the full responsibility, having been blamed for poor practice that resulted in some vulnerable people not being cared for and protected. I consider the data that has been drawn upon to inform change within the profession is flawed and the commentators have capitalised on the growing prejudicial views that have been imposed on to the social work profession as a result of their political position of power and influence.

\subsection{Epistemic Injustice; a new theoretical lens for social work practice}

The social work profession promotes social justice which aims to address actions such as inequalities, prejudice, unequal power and scarcity of resources. The notion of social justice is borne from the promotion of value's relating to the promotion of equality, freedom and independence and is concerned with the distribution of wealth, opportunities, and privilege within a society. In contrast Fricker, (2007) discusses the notion of epistemic injustice which is a study of identity and power and it's convergence with knowledge, morality and politics. This position enables the prescription of the positive values of social justice by exposing the opposing negative outcomes. Therefore, the recognition of the fact and risk of failure in regard to the applied intentions of social justice can be seen when placed under pressure.

Fricker (2007) discusses epistemic injustice that challenges the ethics of epistemic interactions and practice. Epistemic injustice relates to the ethical dimension of two fundamental epistemic practices; "gaining knowledge by being told and making sense of our social experiences" Baoum-Fani Ntavelou, (2017). Fricker, divides this into two sub-sections that refer to testimonial and hermeneutical injustice. Testimonial injustice occurs when a knower's unfavourable perception is imposed onto the speaker that results in the deflation of their credibility. This suggests that a knower's actions and decisions are informed by their own perceptions but the inheritance of prejudice can result in negative and unfair acts of injustice towards the hearer of information. Hermeneutical injustice is a concept that suggests that there is a gap in the conscious 
knowledge of the knower's who have knowingly missed significant information. The absence of knowledge can be caused by "negative identity" (Fricker, 2007) and prejudicial views that this study suggests; if addressed could change the course of action and recommendations by the commentators of reviews, reports and inquiries that have taken place. Therefore, testimonial and hermeneutical injustices are considered to be "forms of discriminatory epistemic injustice, as prejudice against the speaker's identity". Baoum-Fani Ntavelou, (2017).

I consider that an act of testimonial and hermeneutical injustice has taken place towards the social work profession. The recommendations made by commentators towards the social work profession are flawed due to the absence of knowledge that should have referred to the governments financial position to fund statutory duties sufficiently. The act of failing to share this knowledge and make recommendations to address the shortage of funding has resulted in the social work profession being compromised and labelled as a failing profession. The reduction of funding to afford the duties of the profession is seen as a major contributory factor to the challenges that surround the profession, who are now deemed to have failed in their duties to protect the public. I consider the prejudicial views of the knower and neo-liberalism has deleteriously impacted on: the standards and unrealistic expectations of the social worker and their abilty to carryout relationship based social work; the social work profession being labelling as "ill-equipped" and seen as failing in its duties has undermined their position. This negative view has been instrumental in the systematic growth of testimonial and hermeneutical injustice towards the social work profession.

The lack of acknowledgment towards poorly funded services to ensure social workers are a strong workforce, with sufficient resources available to meet the demands of the vulnerable people have not been fully acknowledged by the commentators of the public inquiry, reviews and reports. It is my view that a significant gap in the conscious knowledge of the commentators who have knowingly missed significant information that is referring to the funding of public services, would have changed the course of the investigations that took place. I suggest that should the political agenda have been considered, this could change the direction of the investigator's recommendations and therefore a more balanced and possible justifiable understanding in respect to the data and recommendations would exist. 
I consider an act of epistemic, hermeneutical and testimonial injustice has been carried out due to the failure of the knower's to consider the impact and lack of funding caused by the political agenda. I intend to examine data and the impact as a result of the recommendations that have promoted change in respect to the: the questioning of the social work profession; the professional skill set of qualifying social workers and their readiness to practice in statutory social work; and an exploration into the rationale for the newly emerging routes of entrance into the social work profession.

\subsection{Methodology}

The aforementioned literature is seen to have included the views of social workers in their research although there is a very limited amount of qualitative data that has been drawn and shared of the social workers views and experiences. It is my consideration that whilst social workers were involved in some of the studies, I am unclear what evidence was drawn upon within the overall findings in terms of the social workers views and feelings of their inadequacy to enter into practice. Therefore, it is paramount for this qualitative study to ensure the involvement of qualified social workers, through the adopted methodology of an interpretive phenomenological approach, that aims to ensure social work views and experiences are shared.

Interpretative phenomenological, is an approach that encourages a deeper sense of understanding of a researched phenomenon and is considered integral to qualitative research. The relationship between the individual and the subject is viewed as interactive, and through applied methods of discussion, an insightful and interpretative view of the phenomena can be explored (Creswell, 2014). The adoption of an interpretive position is to enable me to be concerned with accounts, narrative and discourse of the participants (Shaw and Holland, 2014, p.97), and place an interpretative stance in the application of qualitative research. The study will explore the experiences that were aimed to prepare social workers in readiness to qualify and be able to practice effectively within the current climate and diverse communities. The interpretative phenomenological approach is conducive to qualitative research that will bring no reference to statistics of quantitative measures (Strauss \& Corbin 1998, p.11).

To ensure an in-depth understanding of the subject being researched, a literature review is completed to inform this study (Furseth and Everett 2013). It is intended that the review will bring new knowledge and address identified gaps of understanding in order to bring a deeper understanding and rationale towards the reasons why 
decisions have been made. A literature review can provide opportunities to identify specific aspects of the subject that could be enlightening, that were waiting be discovered or investigated (Oliver 2012, P.6). This literature review is intending to gain a deeper understanding of the rationale for the organisational challenges for the social work profession and their justification for questioning the professional skill set of social workers alongside their readiness to practice. It is also intended to seek out reference to the political agendas and the importance of funding that has impacted on the profession.

Following comparisons of other examples and a typology of literature reviews analysed by Grant and Booth (2009), a narrative approach is seen as appropriate due to my intentions to independently select data that allows for identification, summaries and critiques. This approach is conducive to inform the size, type and focus of this study being undertaken and will offer a flexible and original approach (Collins and Fauser 2005). However, it is important to recognise that due to the selectivity of data, the possibility of epistemic hermeneutical injustice is present, as the data drawn could be seen to support the authors view on the subject (Grant \& Booth, 2009). Therefore, I will ensure a critical view is applied and acknowledge the risk of bias resulting in a hermeneutical epistemic injustice being served.

The shared discoveries of a literature review is aimed to contribute to changes in concepts of understanding, social policy and possible future research possibilities (Smith \& Noble 2016). The findings of this research is intended to benefit policy makers and the social work profession. The interviews and data findings with the qualified social workers over the past four years who are statutory social work practitioners, will provide an understanding of their views in terms of their experiences and views of educational routes into the profession. The data is intended to: identify the participants felt they were equipped to enter into statutory social work practice; to explore what the social workers feel are some of the necessary knowledge, skills and qualities to enter into practice.

\subsection{Research ethics}

As a researcher and a registered social worker, I have a responsibility to work within a Code of Ethics (HCPC, 2017). Two key requirements are: to ensure engagement in ethical debate with colleague and employers, share knowledge and take responsibility for making ethically informed decisions; to engage in ethical processes to seek 
changes in policies, procedures, or possible improvements to services or working conditions as guided by the ethics of the profession (BASW, 2015). Therefore, with research ethics and social work ethics being coterminous with and "occupy the same territory in terms of subjects, fields of interest and audiences" (Shaw and Holland, 2014, p.103) the principles and standards will be adhered to for the value and purpose of this study.

\subsection{Study aims}

The aim of this study is: to explore the professional skill set social workers consider are crucial for current statutory social work practice.

The study objectives are:

- To consider the impact of public and social discourse that has surrounded the social work profession since the 2001 Lord laming Public Inquiry that relate to: the regulatory body that informs the profession; the parliamentary responses and the data that influenced the change and impact on the profession; the historic and new routes of entrance into the social work profession.

- To undertake qualitative interviews with social work practitioners who have entered into the social work profession through varying access route of entrance and have been in statutory practice since 2016.

- To explore what is considered a professional skill set ascertained by the views of the commentators alongside prolific writers for the social work such as: Professor Pamela Trevithick; Professor Neil Thompson and David Howe and Dr Ray Jones, who have publicly challenged social policy, power, equality and within the organisations of which we work, and the communities in which we live.

- Epistemic, hermeneutical and testimonial injustice has never been applied as the theoretical underpinning that enables a critical view of a social work. Therefore, I will apply this theory and consider its effectiveness in order to identify and draw conclusions to the study.

\subsection{Chapters}

Chapter One: This chapter introduces the motivation, aims and objectives of the study. A brief introduction and understanding of the methodology in respect to Interpretative phenomenology and a narrative approach that aims to inform a qualitative study is explained. An introduction to the complex matrix of the social work 
profession is provided. The concept of epistemic testimonial, hermeneutical injustice is introduced that will be used as theoretical framework to explore the political position and influence of the government towards the social work profession.

Chapter Two: This chapter provides an outline and summary of the social work and its relationship with the British Association of Social work (BASW). A chronological order of the changes in regard to the social work regulatory body and its impact on the social work profession has been provided. The key focus of the study is in reference to framework's that aim to inform the professional skill set for the social work profession. As a result of the changes, the study highlights some of the positives and challenges these changes have impacted the profession itself.

Chapter Three: This chapter provides an insight into the political agenda over the past 50 years. The data shared provides a deeper insight into the decisions that motivated and informed the changes that were imposed onto the social work profession. The aforementioned literature has been examined with subsequent discussions in response to the commentary made towards the social work profession and the professional skill set of a qualifying social worker. The discussions identify the tensions that exist due to the presence or absence of discussions relating to the responsibilities and recommendations of the government towards care and protection and the possible presence of hermeneutical injustice.

Chapter Four: This Chapter provides an outline of the long-established route of entrance into the social work profession and the new fast track routes of entrance. The overview of the new work based learning routes of entrance into the profession are critiqued in regard to the taught models and work based learning that aim towards developing the expected professional skill set for the profession. The discussion intends to provide an understanding of the tensions that exist in respect to the standards and expectations of the educations routes of the social work programmes.

Chapter Five: This chapter provides the rationale for the chosen methodology, method and thematic processes that were considered conducive and applied to the qualitative primary. The discussion's highlight the strengths and challenges of the intended plan and a critique of the pilot interviews that resulted in the need to change aspects of the original plan for the chosen methods of semi structured interviews and telephone interviews to take place. 
Chapter Six: This chapter refers to the first three of the five stages to the study. Stage One; the opening stage, is a brief referral to the ethics process: stage two; the introductory stage, offers an understanding of the diversity of the participants with reference to entering into social work education of the participants and the limitations of the study: stage three; the transitions stage, provides a summary and discussions in regard to the "assessed year in employment" (ASYE) of a qualified social worker, relating to two common themes identified and how this relates and impacts onto a social workers professional skill set.

Chapter Seven: This chapter examines the data gathered and explores the social work professional expectations on its historic and fundamental expectation of a wideranging body of the professional skill set. Discussions refer to the themes identified which are; theory and practice based learning; statutory practice versus relationship based practice; leadership and management; the concerns of epistemic injustice: to ensure a critical view the writings of prolific writers for the social work profession such as, Professor Pamela Trevithick, Professor Neil Thompson, Professor Aiden Worsley; David Howe and Dr Ray Jones, have been considered to bring informed research and understanding to the themes being explored.

Chapter Eight: To conclude this study; final discussions are provided relating to the tensions that have been considered between the values and duties of the social work profession; the regulators and non-regulator for the profession and the aims to inform a professional skill set for the profession. Further views are also provided in regard to the educational routes into the profession; the consideration to theories of epistemic Injustice and personal thoughts and concerns for the future view for social work. 


\section{Chapter 2}

\section{The Regulatory Framework for Social Work and BASW}

\subsection{Local authorities and social work}

Statutory social work practice is carried out by qualified professional social workers who are employed by local authorities. The duties, roles and responsibilities of a social worker are informed by law i.e. the European Convention of Human Rights (1998) and as mentioned earlier, the Children Act (2015) and the Care Act (2014). The government have commissioned local authorities to hold responsibility for the implementation of law. Local authorities, through interpretation of the law, develop policies and procedures that guide statutory social work teams and social workers to carry out these duties. The policies and procedures that are underpinned by such laws are aimed to respond and provide the support and services that are responsive to the needs of their rural towns and communities, and fulfil the requirements of their duties. Therefore, the social workers and local authorities are informed by law, policies and procedures that task them with the duties and responsibilities, to care, support and safeguard the wellbeing of people, their families and the communities in which they live and adhere to the professional standards set within the profession.

\subsection{British association of social work (BASW)}

The standards of practices applied by social workers are underpinned by a professional and internationally informed value base. The social work practice, standards and values, of the social work profession, are seen to be respectful to empowerment, diversity, and responsive to the multi-cultural society made up by rural towns and communities within the United Kingdom. These values and standards within England are supported by an independent organisation that is funded, held and informed by professional social workers referred to as the British Association of Social Workers (BASW). BASW, is the UK's professional membership organisation for social work and are an independent voice for the social work profession and are not a governing-led body. Their aim is to inform and advocate for the achievement of the highest professional standards within social work practice.

The characteristics, key purpose, understanding and endorsement of BASW is in respect to the social work values, principles and the requirement of a professional skill set in order to practice within the social work profession. The values and ethics defined by BASW refer to the promotion of human rights, social justice and professional integrity that encapsulate a body of ethical principles held by the social work profession 
and align to the values and principles for International social work. The understanding and endorsement of these values, principles alongside the requirement of specific skills and knowledge form part of the characteristics to become a qualified social worker and are associated directly with the profession itself (Beckett and Maynard, 2009, p.69). Professional qualified social workers have the opportunity to opt in via a fee and become members of BASW. However, not all qualified social workers will opt into BASW but the endorsement of the values and principles to the profession are still an expectation within the social work profession.

BASW was formed as a direct response to the Institute of Hospital Almoners and the Association of Hospital Almoners who formulated a voluntary professional register. BASW alongside social work professionals and commentators for the profession have engaged in many significant debates in regard to whether a regulatory or nonregulatory body should be responsible for the registrants of the social work profession. Regulatory, meaning a profession that is a non-departmental public body led by government, or a non-regulatory, meaning it stands as an independent body outside of government. For the purpose of this study, an all encompassing term will be referred to as a registering body when referring to both bodies or its own term unless it is necessary to provide an understanding of their singular positions within the context of the discussions.

"The British Association of Social Workers is the professional association for social workers in the United Kingdom (UK). The Code of Ethics states the values and ethical principles on which the profession is based. The Association has a duty to ensure as far as possible that its members discharge their ethical obligations and are afforded the professional rights necessary for the safeguarding and promotion of the rights of people who use social work services. People who use social work services may be individuals (children, young people or adults), families or other groups or communities" (BASW, 2014).

\subsection{The regulatory body for social work}

The first attempt to set up a non-regulatory body for social work with its own framework of ethics was in 1907. This was at a time when many occupations sought to be recognised for their expertise and "claims of having an extraordinary knowledge base" (McLaughlin, Leigh and Worsley, 2016). During the period of 1971 to 2001, the Central Council for Education and Training in Social Work (CCETSW) who had been 
concerned with the education and training for social work, formally became the regulatory body to oversee the education and training of social workers. CCETSW were responsible for the introduction of a two-year generic qualifying programme which enabled social workers to qualify with a: Certificate of Qualification in Social Work (CQSW) the Certificate in Social Services (CSS) award and a later developing award, the Diploma in Social work (DipSW). The DipSW offered a generic teaching programme and a specialised pathway within its teaching programme that provided a new route of entrance into the profession (McLaughlin, Leigh and Worsley, 2016). The respected content of learning was intently prescribed by six core competencies and the view that social work students should focus on learning competencies that were centred around work-based learning (WBL). The training functions focused on what "social workers are, rather than what social workers do" (CCETSW, 1991) within different placements. Therefore, the WBL promoted the values of relationship based social work practice and was at the forefront of every qualifying social workers practice (Doel and Shardlow, 2005).

Following the election of a new Labour government in 1997 and the implementation of the Care Standards Act (CSA) 2000 on 1 October 2001, CCETSW was abolished by the government as a direct response to Lord Laming's public Inquiry (2001) and its functions were transferred to four new non- regulatory organisations: The General Social Care Council (GSCC), the Scottish Social Services Council (SSSC), the Care Council for Wales (CCW) and the Northern Ireland Social Care Council (NISCC). It was at this time the four nations: England, Scotland, Northern Ireland and Wales became divided. A graduate route of entrance for the social work profession within HEl's emerged and has opened up possibilities of teaching and training social work students from the age of $18+$. The emergence of the HEl's model for the social work profession introduced an increased level of teaching in respect to skills, knowledge's and characteristics that surround the social work profession. The new model continued to provide the established work-based learning opportunities in different placements that are dispersed amongst statutory private and voluntary organisations, which are referred to as practice-based learning. The combined model of teaching and practice is seen to increase and improve the taught element for the social work profession and provide opportunities for the integration of a strong theoretical base to inform practice. 


\subsection{The general social care council (GSCC)}

The GSCC for England was a non-departmental public body of the Department of Health (DfH) in the United Kingdom. The organisation became the independent regulator of social workers and social work students between 2001 and 2012. GSCC had a statutory duty to promote high standards of practice and professional conduct (McLaughlin, 2007). In 2002, they published the National Codes of Practice for Social Care Workers and Employers, and in 2003, the Social Care Register was introduced (McLaughlin, 2010). A significant difference between CCETSW and the GSCC was the title of social worker, which became protected with social workers then needing to apply to join the social work register in order to practice: This registration holds all qualified social workers to account for their practice. Therefore, GSCC were placed with the responsibility to respond to alleged cases of misconduct and held the power to remove someone off the social care register if the complaint was upheld through a tribunal process.

The GSCC were also responsible for the implementation of the National Occupational Standards (NOS's), that were developed by standard setting organisations who consult with employers and other stakeholders across each of the UK nations. The intention and eventual implementation of the NOS's was to inform a standard professional skill set to include a framework for training programmes, measures of workplace competence and influencing job descriptions (Skills for Care, 2006). The NOS's were seen to be much more open ended in comparison to the six competencies borne by CCETSW in regard to where, when and how the NOS's can be achieved in practice (Doel and Shardlow, 2005). The NOS's became the educational framework and was embedded within the social work training programmes across England thus changing the long-standing specific skills set of competencies that CCTESW had established for the social work profession.

\subsection{The social work task force (2009)}

In 2009 Moira Gibb CBE - was commissioned by the Department of Health and the Department for Children, Schools and Families to undertake a comprehensive review of frontline social work practice. Experts within the profession were included to undertake a detailed review of the social work profession referred to as the social work task force. (SWTF). The SWTF was set up in response to the death of baby Peter and the subsequent media attention that lambasted the social work profession. (Jones, 
2014; Parker and Doel, 2013; Warner, 2015). The intentions of the SWTF was to make recommendations for improvement and reform of the whole profession across adult and children services and bolster the resilience of the profession.

The SWTF report (2009), spanned across adult and children services with positive commentary and evidence to be found from the voice of service users to inform the report. Within the overall findings, social workers, were not seen as being confident or competent professionals. The review also undermined the historic infrastructures of teaching and learning for social work students at the time. There was recognition within the report that social work in England was falling short of some fundamental conditions that weakened the potential for its success, referring to "recruitment, retention, frontline resources, training, leadership, public understanding and other factors that are all compounding one another" (SWTF Report, 2009, p.5). This was seen to be preventing the improvement and developments needed within the profession and impacting on the expectations and outcomes for the service users with whom the profession serves.

\subsection{The college of social work}

The Labour government published and acted upon the findings of the SWTF which led to the creation of the social work reform board (SWRB) and the evolution of the college of social work (TCSW). The SWTF and SWRB laid foundations to ensure the on-going commitment for the development of a professional skill set to inform social work practice through the development of the Professional Capability Framework (PCF). The PCF was created to explicitly inform initial social work training, continuing professional development, performance appraisal and career structures for the social work profession of which HEl's integrated within their programmes. However it was found that not all local authorities adopted the PCF model to inform their career structure for the profession.

The configuration of TCSW was intended to be led and funded by the social work profession with its aims to take the reforms forward to improve the status and standards of the social work profession. The decision to develop TCSW brought a level of confusion and conflict to the profession as it resulted in the existence of two professionally funded and driven organisations supporting and informing the profession itself. The aforementioned readily established BASW maintained its presence and remained a professionally funded, operational organisation, albeit 
weakened in its leadership and shaping direction of standards of practice to the profession at that time.

In 2016, the TCSW was closed although the PCF was preserved by its guardian, BASW. In 2017-2018, the PCF was modernised and a newly created professional capabilities framework is the "profession-owned" cornerstone of social work education and professional development in England". (BASW, 2018).

\subsection{The health care professional council (2012)}

In 2012, the GSCC were abolished by the Conservative/Liberal Democrat coalition government with the planned intentions for the regulating body for social work to be held by the Health Care Professional Council (HCPC). The HCPC are an official independent body formed in 2003 and their core purpose is to protect the public and approve professional training programmes for health and social care providers. Therefore, the HCPC hold the responsibility of maintaining a register of all those who with the protected title of "social worker" and can practice as a social worker, which is seen as essential to ensure the standards and principles of qualified social work practitioners are upheld. The change to the HCPC was significant as the new regulatory body introduced a further set of standards and principles that would inform the practice of social work professional workforce. The frameworks were referred to as the Standards of Proficiency (SoP's) alongside the Conduct and Ethics for Practice (HCPC, 2014).

The standards refer to a newly defined professional skill set that became the framework for teaching and assessment within social work education and to inform on-going professional development. A further significant change to the profession with the HCPC is, unlike the GSCC they do not register social work students. The management of social work students conduct became the responsibility of the university and it became the HEl's responsibility to inform the HCPC of the successful outcomes of social work students qualifying. This enables all newly qualified social workers to apply for registration and enter into the social work profession in order to be able to register as a qualified worker.

\subsection{The knowledge and skills statement (KSS)}

The KSS (2014) framework was introduced to the social work profession with the original intention to inform practice standards and professional development of early career practitioners. The KSS was initially developed for children and family services 
and was separate to the KSS for adult services (2014) implemented by the Department for Education (DfE) (2014). However, it has since become one of the assessment frameworks for the new routes of entrance within the qualifying Postgraduate or Master's year of practice. The KSS's have since been used as part of the assessment framework for the new routes of entrance into the social work profession alongside efforts to embed them into the PCF framework itself. Therefore, the profession is now experiencing learning outcomes and further changes in the standards and assessments at qualifying levels from the differing routes of entrance into the profession. The outcomes to become an effective social worker through some of the new routes of entrance refer to; emotional resilience, understanding social work theory and research, awareness of risk and harm, intuition and logic in decision-making, accurate recoding skills for child and family assessments, and an understanding of the Knowledge and skills statement for social workers.

\subsection{Social work England}

In 2017, The Children and Social Work Bill 2017, proposed new changes for the profession by giving the education secretary power over selection and assessment of social workers. The suggestion that the regulatory body be transferred to a nondepartmental government body has brought concern to the social work academics and commentators to the profession. Jones (2017) states, the government want political control over who can be a social worker to be given to the education secretary, alongside the decisions of how and by whom they will be taught, trained, judged and assessed. However, despite protests also supported by BASW, in December of 2019, underpinned by the Children and Social Work Bill Act 2017, it is intended, the professional regulatory body will be handed over to a new government executive agency who will replace the HCPC. The executive agency will become the new regulator for Social Work referred to as; Social Work England (SWE). The agency is accountable to the education secretary and based in the Department for Education (DfE) and supported by the DfE and Department of Health (DfH) with both departments sharing responsibility for social work policy.

\subsection{Discussion}

The outlined historical view of the social work profession and its relationship with both a regulatory body and BASW has provided an understanding of the values, standards and principles that have informed and shaped the social work profession for over 100 
years. The tension can be seen in regard to the profession being led by both regulatory and non-regulatory bodies that support both the legal duties and promote the values of relationship based practice. Since the 1970s, BASW are seen as strong advocates for the values and professional skill set for the profession. BASW's contribution to the profession is longstanding and now hold guardianship over the PCF's following the emergence and demise of TCSW by the government. This framework is firmly embedded within the education and training routes of the profession and is a considered expectation that informs different aspect to the characteristics of a qualified social worker. What can be seen within these changes are; CCETSW's reign of over 30 years left a lasting impression on the teaching and training that enabled qualifying social workers to access the profession. The latter regulatory bodies have all held their position for a minimum of four and a maximum of seven years with all organisations implementing changes to the regulation framework that informs the whole social work profession.

The positives of these changes are in respect to, the profession now being recognised as a robust profession that is worthy of regulation and the title of social worker is protected. Social work practitioners are held accountable to uphold the standards and values of the profession and carry out their legal duties. It is also recognised that a significant difference was made to the profession by ensuring local authorities and HEl's endorsed the PCF as a practice standard that informed the professional development framework and ongoing standards for registration which brought a level of consistency across England.

The challenges are in respect to the frameworks that have required educational routes of entrance into social work and local authorities to adjust their programmes to ensure that qualifying social workers operate to the standards they have imposed. However, the tension that exists is in respect to: the SoP's and PFC's that refer to knowledge, skills and qualities for the profession but they do not relate to definitions of the types of knowledge and skills that should be held and applied in practice. The SoP's and PCF framework refer to what social workers should do rather than who social workers are in comparison to CCETSW's core competencies. A further tension relates to the issues of time. It would seem, due to the rapid and numerous change that have been endorsed on the profession, no true value of time has been afforded that would enable a critical evaluation of the impact from the dual frameworks of BASW and HCPC. 
Therefore, the opportunity to critically evaluate the professional skills set of the social worker has not been fully completed in order to consider if they constructively aligned between what is being taught and the currency of needs in modern day statutory practice. 


\section{Chapter 3}

\section{Literature Review - Public and Social Discourse}

\subsection{Victoria Climbie}

The struggles of the social work profession by the professionals alongside the concerns of epistemic injustice that are to be explored pre-date and go beyond the capacity of this research. Therefore it is with the utmost respect to all the vulnerable people who will remain unmentioned but present in thought who have been subject to; inadequate support, acts of neglect and abuse by others and loss of life prior to and following the year 2000. Victoria Climbie tragically died on the 25th February 2000. Victoria came to the United Kingdom to live with her great aunt and her partner, with her parent's belief that she would have a better life. Victoria, whilst known to health and social services became a victim of unimaginable cruelty and died at the hands of her great aunt Marie-Therese Kouao, and Carl John Manning who were eventually convicted of her murder.

In April 2001, Lord Laming was asked by the secretary of state to chair an independent statutory public Inquiry following Victoria's death, to make recommendations that would aim to prevent such a tragic event occurring again. In his findings Lord Laming stated that "the suffering and death of Victoria was inexcusable and was seen as "a gross failure of the system" (Laming 2003), with fundamental expectations of basic good practice being absent. The report went on to state that all the agencies involved and "empowered by Parliament to protect children in positions similar to Victoria's funded from the public money - gave a low priority to the task of protecting children. They were "under-funded, inadequately staffed and poorly led". (Laming 2003).

\subsection{Baby Peter}

In the light of Victoria's death seven years previous a serious case review and public Inquiry was inaugurated after the death of 17 month old baby Peter who died on the 3rd August 2007, while under the care of police, doctors and social workers. Peter suffered more than fifty injuries over an eight-month period enforced by his mother Tracey Connelly, her boyfriend Steven Barker, and Jason Owen (Steven Barker's brother). Regulation 5 of the Local Safeguarding Children Board Regulations 2006 requires local safeguarding children boards (LSCBs) to undertake reviews of serious cases in accordance with procedures set out in chapter 8 of Working Together to Safeguard Children (2006). 1.1.2 When a child dies, and abuse or neglect is known or suspected to be a factor in the death, the LSCB should conduct a serious case review 
(SCR) into the involvement that organisations and professionals had with that child and their family.

The response was motivated by the magnitude of Peter's injuries but also because the local authority and statutory services responsible for his care and welfare was the local authority, health and public services who had been found to have failed to care and protect Victoria. Mor Dioum, the director of the Victoria Climbié Foundation that was set up to improve child protection following Victoria's death claimed that Haringey council did not implement the recommendations of the Laming report and claimed "systematic and operational failures" by the local authority. Public outrage was also raised which Dr Ray Jones considers was as a direct result, caused by media attention that turned on those who worked to protect children who became the focus of the reporting and of the blame, especially the social workers and their managers (Jones, 2014)

\subsection{Lord Laming report (2009)}

In November 2008 Lord Laming was commissioned by the Children's Secretary to complete a report on the progress of the implementation of reforms introduced after the Victoria Climbed Inquiry in 2003. Lord Laming's Progress Report; The Protection of Children in England (2009) became heavily critical of teaching and training of social work, public services, social work practice and community services. The report made 58 recommendation for change for the leadership and practice within children services which aimed to improve the standards of care and protection for vulnerable children. The report made reference to social work practice that referred to a professional skill set, to be assured social workers are highly skilled and equipped to be able to carry out their duties in practice within children's services. A recommendation was "to ensure that all professionals involved in keeping a child safe share information, assess risk, and make decisions effectively together to keep children safe" (Laming, 2009). It was also recommended within this report, the need to consider different routes of entrance into the professional that placed greater emphasis on practice experience within social work teaching models.

\subsection{The Munro report (2011)}

The Conservative and Liberal coalition government came to power in 2010. It was seen to want and need its own plan for social work reform, particularly in children's services as a response and result of the death of baby Peter. The government 
commissioned Professor Eileen Munro, a former social worker and respected academic at the London School of Economics to carry out a detailed review of child protection. The report included a diverse group of professionals involved in health and social care, to include social workers, managers and service users and was defined as one of the most "comprehensive, sophisticated and analytically refined reviews ever to have been undertaken" with far - reaching recommendations for improving children's social work (Gray, Midgley and Webb, 2014, p. 8). Munro's report was respectful of local authorities and the possible reasons why social workers were policy and administration driven in practice, she also expressed significant concern about the taught route of social workers and the skills and knowledge base required.

Within the findings and in respect to applied practice of social workers, Munro expressed her concern of the loss of relationship-based practice by practitioners based in statutory settings who had become very concerned with complying to procedures and regulations. The report exposed "a bureaucratic, top down, directive, managerial approach" (Munro 2011). Munro stated - relationship based social work had been ground down and compromised in favour of responding to the pressures borne upon them to carryout legal duties. These concerns identified the conflict between the demands of statutory social work practice and the diminishing importance of relationship based social work practice. The principles and values of the profession were being seen as highly compromised within statutory social work in comparison to the practice that was seen by social workers within non-statutory settings.

The Munro review expressed concerns of educational curriculums that were seen to be inconsistent and noted specific absence of taught modules relating to the importance of: evidence-based methods of working with children and families; knowledge of child development; and communication with children and young people: It was suggested that theory and research were not aligned in respect to what is taught and the realities of contemporary social work practice (2011, p. 97). The Munro report went on to question the singular academic route of entrance and suggested that the reason for poor and failing social work practice was seen as; a result of not all newly qualified social workers who are emerging from degree courses holding the necessary resilience, knowledge, skills or areas of expertise required to undertake the role and responsibilities required when entering into the profession. Munro argued the need for 
infrastructures to be reviewed that will bring change and improvements to social work and she advocated the need to improve the expertise of social workers:

"Not all newly qualified social workers are emerging from degree courses with the necessary knowledge, skills and expertise, and they are especially unprepared to deal with the challenges posed by child protection work. Degree courses are not consistent in content, quality and outcomes - for child protection, there are crucial things missing in some courses such as detailed learning on child development, how to communicate with children and young people, and using evidence-based methods of working with children and families. Theory and research are not always well integrated with practice and there is a failure to align what is taught with the realities of contemporary social work practice".

Within the review, the political climate and fear factor that was present was not highlighted in the report as a possible reason for impact. The report offered no reference to the International social work intentions and very little detail to the impact of; the political agenda on public services; social work posts being reduced and poor outcomes for service users as a result of reduced public spending. Greater challenges were being experienced as a result of social workers, who were attempting to follow through policies and procedures to carryout safeguarding duties. Alongside the need to continually develop their professional knowledge and skills to ensure they could respond to the increased demanding unmet needs of multi-cultural towns and communities. Inference was made that social work practice was as a result of poor teaching or ill-equipped teaching programmes without reference or consideration or evaluation to the relationship based social work practices that were known to be taking place within non-statutory settings.

Andy McNicoll (2017) reflects on the political climate and media intrusion that exposed the difficulties of the baby $P$ case into the public arena. Sharon Shoesmith (Director of Children service Haringey) became victim of the baby $P$ case, as she was removed from her post and was held accountable for the poor practices within the Haringey Local Authority, alongside other social workers who were all eventually dismissed. Nicholl discussed a "A climate of fear" in the aftermath of these responses that seized social workers across the country, alongside a cascade of child protection referrals 
and children being taken into care. This perspective fully endorsed the original expectations and findings by Eileen Munro, that systems and processes had taken priority over good relationship based applications.

In regard to the issue of government responsibilities, with further examination of the report, no reference was made towards the growing issues of climate change or the governments neo-liberal agenda's and the impact this was having on the social work profession.

\subsection{Professor David Croisdale-Appleby review (2014)}

In 2014 a review was a commissioned and led by Professor David Croisdale-Appleby. (Croisdale-Appleby, 2014) The aim of the review was to determine if the reforms regarding the integration of a changing education with a new curriculum framework and practice were ideally structured to meet the requirements of the social work profession. Similarly to the Munro report, this review was planned to ensure the complex matrix that existed within the social work profession was inclusive of all stakeholders that encompassed; educators, a range of multi-disciplinary professionals, service users and carers, social work practitioners and students. The aim was to gain as broader view as possible of the integrated efforts of education and practice. Further intentions were; to consider the social work journey from recruitment to education to qualifying levels to become a practitioner and through supported practice aim to recognise then needs of continuing professional development throughout careers.

Professor Croisdale-Appleby's review shared the anxiety and impact in respect to the political agenda and austerity that had been imposed on the social work profession and other involved public services. Croisdale-Appleby referred to social workers being ill-equipped to practice within the current regime of process driven practices and acknowledged the issues of staff shortages and increasing demands and pressures being placed on social workers that are impacting on the standards of practice. Further concerns related to: the emerging new "fast track" routes of entrance into the profession with pre-qualifying specialism's; the risk of taught modules within the new fast track routes providing insufficient levels of taught modules that are considered major attributes of a qualifying social worker who are able to sufficiently demonstrate a professional skill set in practice. A model that is being reflected within a majority of 
professions within England and across Britain relating to e.g. education, policing, nursing, allied health and medicine.

Unlike the reports that preceded Croisdale-Appleby, within his review, the anxiety and impact in respect to the political agenda that has been imposed on public services was recognised and acknowledged. The review also shared concerns that the new routes of access to the profession through the emerging fast track specialised routes had raised controversy amongst the profession itself. Croisdale-Appleby contradicts the original recommendations that new routes of entrance will and could address the issues of social workers becoming more equipped to practice upon qualifying. Croisdale-Appleby reports on the new routes of entrance that they;

"will not offer opportunities for adequate internalisation of some of the major attributes knowledge, skills and capability of application in a sufficiently representative range of practice which educators feel newly qualified social workers should possess." (Croisdale-Appleby, 2014)

The review provided conclusions and recommendations that aimed to further reshape social work education and the profession. For the purpose of this study two of the interdependent recommendations made by Croisdale-Appleby (2014) are; Conclusion 6: that regulations are appropriately strengthened to encourage alternative routes to the social work qualification and that the fast track routes should be available to contribute to adult social care. Conclusion 8: that the proposed alternative educational routes to qualification should be required to demonstrate the pedagogical evidence that adequate knowledge equip students for a career.

Croisdale-Appleby report (2014) discussed the orchestration for social work education and training that should be directed at developing social workers whose professional profile is comprised of three components: "the social worker as a practitioner, the social worker as a professional, and the social worker as a social scientist" and that "qualifying education as the process by which social workers are equipped with the capability to enter the profession ready to engage in practice as newly-qualified social workers. "Croisdale-Appleby acknowledged concern related to; the regulating body not providing the saliency and depth required; the notion of specialised routes of entrance into the profession; the emergence of different qualifications and the potential fragmentation this could cause throughout the social work force; the commitment to 
generic teaching for practice by reducing teaching times and guaranteeing two differing placements in statutory settings could compromise and limit student learning:

"There is anxiety that such courses through their focus on pre-qualification specialisation will not provide a sufficient knowledge and practice of research, coverage of the underpinning theoretical basis for understanding human and society's behaviours, nor an adequate internalisation of some of the major attributes (knowledge, skills and capability of application in a sufficiently representative range of practice) which educators feel newly qualified social workers should possess. These views are widely held, and I would suggest that one of the real issues underlying this anxiety is whether the current regulatory framework of the HCPC and the endorsement framework of TCSW are of sufficient breadth and saliency and will be applied with sufficient rigour to ensure that the courses which fall into this category". (Croisdale-Appleby, 2014)

\subsection{Sir Martin Narey - Independent report (2014)}

Sir Martin Narey (2014) completed an independent report of the education of children's social workers. The objectives were to view the initial education of children's social workers, with the intention of advising on whether improvements had been made based on the reforms of the Munro report (2011). The focus of this report was to review the impact upon the basic training of social workers. The chosen methods of the review in order to gain this information was drawn from private interviews with employers, academics, students and newly employed, established and retired social workers.

It is found within this report, a theme emerging relating to the questioning and suggestions of development for routes of entrance into the profession. Narey (2014) suggests that different levels of experience and abilities should be valued and welcomed into the profession and not all social work practitioners require a Masters qualification for entrance into the profession. Initial commentary within the review relate to the SoP's that were seen as too generalised and not representative of the social work profession in regard to its requirements and responsibilities of qualifying social workers. It was considered that pre-qualifying students need to acquire a basic professional understanding sufficient to allow them to begin practice safely and competently. 
Narey (2014) equated the SoP's standards to those in medicine for training doctors and considered the challenge for the social work profession that is to seen as responsive and accountable to the HCPC (2013). Akin to other professions as previously mentioned, the concerns Narey held was for the need of the social work profession as having to respond to the interwoven, complex regulations and generic wording of five regulators that informed the current regulating body for social work. Narey (2014) argued that the standards were complicated as they were interwoven with other standards such as; the 10 standards of conduct, performance and ethics (HCPC, 2012), Standards of Education and Training Guidance (HCPC, 2018), The College of Social Work (2014), and the Professional capability Framework (BASW 2012,2018 ), that inform the profession as a whole and the Benchmark Statements for Social Work, produced by The Quality Assurance Agency For Higher Education (QAA).Whilst dissatisfaction was shared in respect to these regulations and standards, Narey did suggest that the nine domains of the PCF's (BASW, 2012) whilst somewhat were seen to be a significant improvement compared to the Standards of Proficiency (HCPC, 2013) both of which inform the HEl's education and training alongside informing the ongoing professional development of the social workers who remain engaged within the profession.

\subsection{Discussions}

\subsubsection{Public and social discourse}

In response to the public outrage when tragic cases such as Victoria and baby Peter meet the public's attention, it is understandable that inquiries and serious case reviews must be held. Actions are initiated as it is demanded by the public and professional's alike that an understanding how and why such horrific acts can go unnoticed. However, when there is a loss of life, almost inevitably, the first question is often "whose fault is it" (Douglas 1994).

Many of the changes imposed upon the profession that were transported from the collective recommendations of the Inquiries, reviews and reports can be seen as developmental for the profession. The earlier mentioned deliverance of the recommendations of the aforementioned SWTF and the emergence of TCSW activated changes that made a significant impression on the profession. This was particularly relevant with the, now established professional capability framework that aims to standardise a career structure for the profession and inform the professional 
skill set for the social work profession. It can be seen as a model that has been responded to by local authorities and universities and captures the professional skill set journey and continuum of learning for the social work profession. Narey's view (2014) of the PCF was supportive of its commitment to on-going professional development within the social work profession. Narey stated that the nine domains of the PCF's (BASW, 2012) were seen to be a significant improvement compared to the SoP's (HCPC, 2013). Although, Narey also expressed his understanding and disapproval to the confusing and complex matrix in respect to the regulations and standards that had been imposed on social work to inform the professional skill set of a social worker.

\subsubsection{Relationship-based practice - Statutory practice}

The tension identified within the Munro report refers to the change in methods of working that have impacted on professional practice and compromised the historical methods of relationship-based practice. This method of intervention is considered as a preventative, educational and supportive model and seen as an effective method of positive partnership working that can improve the outcomes of people's lives within the social work profession (Ruch, Turney and Ward, 2018). In many situations, relationship-based practice is seen to prevent the need to activate more severe measures of legal interventions which remains a key intention of social workers who practice within both statutory settings and non-statutory organisations.

Therefore, it can be seen that the shift from the application of relationship-based practice to be replaced in favour of defensive systems and administrative processes has been taking place since the early government interventions and recommendations of Laming inquiry and report that placed harsh criticism and blame on the systems, operations and practices of the social work profession. I consider, the diminishing possibilities to apply relationship-based practice is due to the increasing demand of social workers needing to carryout safeguarding procedures and that no acknowledgment was made to the broad base of social work and the practices that are carried out into the wider areas within non-statutory services. It is also recognised within Croisdale-Appleby review that further tensions being experienced within the profession was as a result of staff shortages and reduced funding. The lack of funding and an increase in responsibly of duty to care and protect has placed increasing levels 
of pressure onto the diminishing social work practitioners and has compromised the possibilities of preventative models of working such as relationship-based practice.

\subsubsection{Epistemic and hermeneutical Injustice}

Within the commentaries of the literature reviewed, I consider the leaders have caused systematic acts of hermeneutical injustice. The leaders of the commissioned reviews and reports, being the knower's have blamed and criticised the systems and practices taking place within the social work profession, and they have consciously made no reference to the government powers, responsibilities of funding to afford the profession or make recommendations to increase public funds. The initial findings referred to within Lord Laming's public Inquiry in 2001 acknowledged concerns of the profession being "underfunded, inadequately staffed and poorly led". However, in Laming's review of 2009, neo-liberalism was unmentioned. The review can be seen as criticising the social work profession and making recommendations that critically impacted on the social work profession and the systems in which they work. The approach between the first and final report of Lord laming offers a clear shift in focus albeit it still critical. Lord Laming removed the focus of the government's position of responsibility to the focus and blame and placed the responsibility on the commissioned services of the local authorities and the poor professional skill set of a social worker.

With respect to Croisdale-Appleby who spoke of issues relating to funding, the broader levels of knowledge of the knower's in respect to the government responsibility and it's absence of funding was not highlighted in any of the following reports. Lord laming in has latter review, can be seen to focus on the profession itself and not consider the wider issues of the governments underfunding that continued to commission the services they had initiated an inquiry for. Therefore, the need to afford the increasing levels of care and safeguarding that is placed upon the profession in order to improve the services being delivered remained unaddressed. Laming was forensic within the investigations but with, what seems to be with the intention of searching for someone to blame, which Kemshall (et al 1997) suggest is very rarely the state.

The repercussions of this level of blame that suggested inadequacies of the profession, resulted in prejudicial, negative views of the profession. This outcome can be seen by its onlookers, who had been labelled by the powerful position of other's (Giddens and Sutton, 2013) and deemed to be failing in their duties to meet the needs of vulnerable people, thus imposing an ascribed negative identity upon the profession 
(O'Byrne,2011). I suggest that the presence of an obscured understanding of the social work profession had been adopted by the "outsiders" of the profession, being the government, the leaders of the government interventions and the growing view of the public. The prejudicial views had accumulated against the profession that impacted on the possibility of wider, positive and realistic, understanding and forward thinking to inform the recommendations made. Fricker (2007) would argue when wrong is analysed in terms of a situated hermeneutical inequality, the prejudicial flaws in shared interpretive resources prevent the subject from making sense of an experience. Therefore, I consider aside to the Croisdale-Appleby review, the findings and recommendations of the earlier reviews and reports all alluded to the impact of neoliberalism and austerity but did not clearly state: the overall responsibility for the funding of care and protection of vulnerable people living with the England belongs to the government; the rising challenges being experienced within local authorities due to climate change and also in terms of decreasing resources and the impact on the methods applied by social workers to support vulnerable people. The presence of hermeneutical injustice has been caused, due to the absence of this knowledge that has brought confusion and raised tensions between the government and the social work profession.

I argue that it is due to Lord Laming's report of in 2001 akin to the later commentaries that followed, have failed to acknowledge the full impact of the neo-liberal agenda, the reduction of funding and its impact on the provision of the social work profession. With no commentary made of the government's lack of responsibility to provide sufficient funding to carry out their duties to the public. Therefore, I suggest that the leader's political position to any of the inquiries, reviews and reports that followed Laming's review were systematically influenced by the Laming review, towards the notion of a failing system and poor practices of social workers at a local authority level. With the reputation of social workers now being seen as incompetent and failing to meet the needs of vulnerable people and not acknowledging the responsibilities of the government I consider the act of testimonial and hermeneutical injustice existed.

\subsubsection{Educational Routes of Entrance into Social Work and the Professional Skill Set for Social Work}

Laming and Narey both expressed significant concern about the singular taught route of entrance of social workers and the professional skill set of social workers. The 
questioning of educational routes was drawn from data that referred to qualifying social workers who were seen as ill-equipped with the necessary professional skill set to meet the challenges of current social work practice. In contrast, the concerns found within the Croisdale-Appleby report (2014) is in regard to; his support of the historic and newly emerging educational routes of entrance into the profession; and the changes that were being experienced within the profession of evolving new programmes that stepped outside of the established generic programmes. The programmes were seen to have been scaled down in terms of teaching and practice allowing social workers to be qualified in a shorter period of time.

The concerns shared are suggestive of compromising the professional skill set of a qualifying social worker by preparing them to work in one area of practice and not hold a generic professional skill set that enabled them to respond to the wider aspects of the work undertaken. Croisdale-Appleby expressed concern, that the new routes of access may produce social worker's who are inadequately informed and qualified to understand the various perspectives in any situation. "The result could be the imposition of simplistic versions of child protection methodology which could lead to selective information gathering and the utilisation of a narrow processing methodology and a consequently narrow view of social work involving children as being only child protection and safeguarding." (Croisdale-Appleby, 2014, p. 27).

The current challenges towards HEl's are as a result of the Conservative government, who are reducing the funding arrangements towards education and training of social workers. With the social work profession now in crisis in terms of recruitment and retention issues, the government are in search of cost-effective models of education to address the recruitment and retention which has become a critical concern within the social work professional arena. Therefore, the funding afforded to social work programmes and bursaries for social work students are being changed. The impact of this shift in funding has severely impacted on the numbers of applications being made to HEl's to train as social workers. In respect to the focus of this study, a critical concern is in regard to how these changes and new routes of entrance will impact on the social work profession and the already questioned, professional skill set of a qualifying social worker. 


\section{Chapter 4}

\section{Routes of Entrance into the Social work Profession}

\subsection{Introduction}

Within qualitative research it is an expected principle that authors consider and become transparent in their awareness, position and motivations throughout the study (Labaree, 2006). In the discussion that follow, I share a concern that presents a possible risk of bias in my critical view of the study. In order to address this imbalance, an objective critical approach is applied to ensure every effort is made to offer a reasonable balance of explored views points. Therefore, it is appreciated that the social work profession has needed to respond to the challenges of austerity and is one of the fundamental issues that is not possible to consider in its entirety within this study is. However, as acknowledged earlier in the study, one of the challenges within the social work profession is in respect to recruitment and retention: my knowledge that impacts this stage of the study is; local authorities are struggling to meet the demands of the needs of the communities due to a shortage of staff. Tremendous efforts have been made to increase the workforces and this is a key reason why there are new routes of entrance into the profession. With respect to this understanding, staff shortages will undoubtedly impact on the day to day abilities and qualities of the social workers and local authorities in their aims to carry out their duties. However, from an educational and practice expectation the importance of developing a professional skill set is critical to the success of social work practice.

For the purpose of this study, the value and underlying principles of social work practice are maintained. The educational routes of entrance to the profession from a generic HEI route of entrance that is informed by the SOP's and PCF's will be the starting position to inform the differences in the currency of change that are taking place. It is to be assumed at this stage of the study, the taught and assessed route of education for social workers in order to determine if they qualifying social workers are equipped to enter into statutory practice is robust and that practice is aligned to expectations of the practitioner. Therefore, it is also to be assumed, if social workers are not equipped with the necessary professional skill set to carry out their duties they would not qualify and enter into the profession. A qualifying student could also be seen to succeed in their qualifying years but it could be suggested that the professional skill set of the student has not efficiently tested, this would ultimately compromise the standards, values and quality of social work practice they aim to achieve. 
Should the latter two possibilities be correct, the routes of entrance into the profession through an education programme would be seen as not meeting their responsibilities. Therefore, the impact would be that a professional skill set has not been taught and assessed effectively to qualifying social workers. The responsibilities could impact on the persons experience and potential outcomes of working with a social worker who has not carried a strong professional skill set to inform their practice. Contrary to this perspective if a social worker is equipped with the necessary professional skill set and benchmark standards are being met, then the practice should not come under scrutiny as the exposure of standards and values are bringing no cause for concern and work towards social justice. However, the standards of practice have brought cause for concern, therefore it is important to consider the acts of government, educational routes, local authorities and social work practitioners in their aims to care and protect the public.

\subsection{Higher education Institution (HEl's) - Generic social work education programmes} The overall aim at this stage of the study is to explore the aforementioned suggested concerns by Professor David Croisdale-Appleby that the risks of compromising the professional skill set for social work exists with the new routes of education. Therefore, it is important to hold a basic understanding of the fundamental reason for fast track routes to enter into the profession in order to consider if compromises have been made to the professional skill set.

Since 2003, the main qualifications for social work in England have been completed within Higher Education Institutions (HEl's) by completing an undergraduate Bachelor's degree (BA, BSc or BSW) in social work or the emergence of a post qualifying Masters Route. These routes of entrance and academic qualification have replaced the previous qualifying award, the undergraduate Diploma in Social Work (DipSW) first awarded in 1991 which was phased out across the UK by 2009. The DipSW also had a postgraduate counterpart, the postgraduate Diploma in Social Work (PG DipSW) and is still awarded. Prior to this, the Certificate of Qualification in Social Work (CQSW) and the Certificate in Social Services (CSS) was the recognised qualification and awarded between 1975 and 1991 by CCETSW.

The introduction of a generic social work degree in 2003 had several ambitious aims. It was set to deliver a generic, teaching and training model and for all social workers, upon qualifying to be borne from a degree that would form an all-graduate profession 
(Halton, Powell and Scanlon, 2013). A further intention was to create a graduate profession that would improve the practice and outcomes for service users and for qualifying students and to promote transferable skills that would enable qualifying social workers to work in their chosen field of practice upon qualifying. The generic programme was also considered as a preferred model to address the decreasing numbers of applicants for social work programmes. At the time of its emergence, the increase in numbers of qualifying social workers was seen as a productive response to the escalating concerns of recruitment and retention within local authorities as a direct result of the increasing number of social workers ending their social work careers prematurely for a plethora of individual reasons within Local authorities (Hussein et al, 2011). In respect to recruitment and retention concerns, records have shown there was an increase in student numbers of social workers training to enter into the profession since 2008. However, despite this increase recent figures show that local authorities are still reliant upon employing high numbers of agency staff to fill their vacancies (Department for Education, 2015).

The programmes, developed as a three year academic undergraduate or two year Postgraduate/Masters route. The teaching plans were developed to promote an experience of learning that provided a balanced approach of taught knowledge, skills and the underpinning values with professional understanding that will inform practice experiences. The model was anticipated to teach and test out the developing knowledge, skills and value base of the profession in applied practice with robust assessment processes in place. Therefore, all programmes were expected to provide two practice placements in two contrasting service settings. Placements were generally seen to be based within a children's setting and/or an adult setting and within the fields of statutory, voluntary and private sector. The expectation was that the practice experience would develop and offer greater levels of complexity as the student progresses into qualifying levels. To ensure social work programmes were viable, all HEl's were expected to enter into a scrutiny process for their programs to be validated. There were no limits in terms of numbers of applicants undertaking social work programmes therefore qualitative evidence had to be provided. It was the university programmes responsibility to work in partnership with the communities and local authorities to build a qualitative programme that met with the standards for the profession. The programmes were underpinned with the values of generic social work. 
The teaching and learning of students and the learning outcomes were aimed to equip students with the necessary knowledge, skills and qualities to undertake any area of social work practice they chose to enter into upon qualifying.

The predominant model was for academic teaching with a wider active system of learning such as a placement learning experience (Wenger-Trayner, 2015). Throughout a social work student training, they will have been engaged in a programme that promoted shared teaching and learning opportunities and robustly assessed them against the previously mentioned PCF assessment framework and SoP's. The PCF has nine common domains of capability that social workers are expected to develop during and following their training. It is seen to support social workers to meet the professional regulatory requirements of the, specific guidance and policy for particular job roles, and is aligned with the IFSW's global definition of social work through the BASW Code of Ethics for social workers across the UK. The assessment framework can be seen to enable students to demonstrate their understanding and level of knowledge, relating to law and policy and legal frameworks. A variance of theories to inform intervention within a generically based education model are taught. Social work students are expected to demonstrate their application of particular core skills detailed within the framework such as empathy, advocacy and communication. Educators are also seen as critical to the successful application of the assessments and hold key positions as the gatekeepers for students to enter into the profession. This suggests that social workers should be equipped to carryout statutory duties and apply the principles of relationship-based practice.

Further intentions of the social work degree were aimed at; creating a graduate profession that would improve the practice and outcomes for service users; for qualifying students to promote transferable skills that would enable them to work in their chosen field of practice upon qualifying; to address the decreasing numbers of applicants for social work programmes; respond to the escalating concerns of recruitment and retention within local authorities as a direct result of the increasing amount of social workers ending their social work careers prematurely for a plethora of individual reasons within local authorities (Hussein, 2011).

\subsection{New routes of entrance into social work}

In respect to recruitment and retention concerns, records have shown an increase in student numbers of social workers training to enter into the profession since 2008. 
However, despite this increase, recent figures show that local authorities were still reliant upon employing high numbers of agency staff to fill their vacancies (Department for Education, 2015). The shift and resistance have been acknowledged within the social work profession responding to the pressure to develop programmes that promote a higher degree of active work-based learning and move away from the traditional models (Perks, Orr and Al-Omari, 2016)

The emergence of; Frontline (2015) Step Up to Social Work (2016), Think AheadMental Health (2014), Social Work Apprenticeship programmes (2018) are all new routes that can be completed to become a social worker. There are several significant shifts that have been introduced because of these changes in regard to: leadership, funding, teaching programmes, timing and assessment processes. In partnership with HEl's, local authorities have been placed with the responsibility to lead in the management of addressing recruitment and retention and have been encouraged to increase their workforce through fast track work-based models of teaching and learning. A significant attraction of the work based learning approach to potential social work applicants is that it is a paid position for training social workers rather than accruing further costs of student fees if taught through an independent academic university route.

The new routes of entrance delivered by colleges and universities must meet the regulators' approval. The current regulators as referred to earlier are the Health and Care Professions Council (HCPC) and the PCF assessment framework held by BASW alongside the Quality Assurance Agency for Higher Education (QAA). The fast track routes, akin to the undergraduate -postgraduate and Masters route of entrance, require local authorities and universities to work in partnership and decide on the programme design, delivery and assessment framework. It became the local authority's responsibility to take the lead and assign trainees to a supervisor for placements and the university to supply a tutor for academic teaching and supervision. Therefore, the predominance of learning and training social worker takes place within the selected teams of local authorities.

\subsection{Frontline}

Frontline is a "fast-track" social work training programme whose pilot phase ran from 2013-2017. It was focused on statutory child protection work in local authorities. The structure and aims of the Frontline programme is dedicated to children and family 
services through a shared teaching and work based learning model. The model is made up of a five week residential for the teaching and training element. "The training model emphasises direct practice skills, with a single over-arching theoretical framework - a systemic model - and teaching of two evidence-based interventions, i.e. motivational interviewing and a parenting programme based on social learning theory" (Department for Education, 2016).

Frontline was opened up to graduates who already held a 2.1 degree and deemed to have qualities to make good social workers. The programmes unique selling point to potential students was its fast track entrance route into the profession compared to the undergraduate programme of three years and a postgraduate or Masters programme of up to two years within HEl's. It is a predominantly practice based learning programme of 206 days in practice to include and 22 teaching days - 30 days of practice within an adult setting over a one year period.

\subsection{Step Up to social work}

In 2013 - Step Up to Social Work was launched by the DoE. It is an intensive, 14month, full-time programme for trainee social workers who are required to work in children services Local Authorities. Through supportive systems, practice experience and opportunities for some teaching, enable trainee social workers to be awarded a postgraduate diploma in social work and become registered, qualified social workers. Step up as with all other routes except for undergraduate programmes is a route also looking to attract graduates with a 2.1 degree with honours or a graduate certificate and as a minimum a 2.2 degree. All qualifying social workers are assessed the against the knowledge and skills statements (KSS) for child and family social workers, the PCF's and the SoP's.

The outcomes to become an effective social worker within the step up programme refer to, emotional resilience, understand social work theory and research, awareness of risk and harm, intuition and logic in decision-making, accurate recoding skills for child and family assessments, and an understanding of the knowledge and skills statement for child and family social workers for children and family services implemented by the Department for Education (DfE) (2014) - which all applicants would be assessed against and to become familiar with the PCF for social workers (entry level). 
The knowledge and skill statements developed by the DfE (2014) as a guiding tool to inform and assess post qualifying social work practitioners to the knowledge and skill development required. The statements have since been used as part of the assessment framework for the new routes of entrance into the social work profession alongside efforts to embed them into the PCF framework itself. Therefore the profession is now experiencing learning outcomes and further changes in the standards and assessments at qualifying levels from the differing routes of entrance into the profession.

With its child and family focus, step up to social work, emphasised and applied the postgraduate intentions of knowledge and skills for child and family practitioners of (Department of Education, 2014). The knowledge and skills framework was originally intended to inform standards and professional development of early career practitioners but has become one of the assessment frameworks for fast track programme assessments in the qualifying Masters year of practice.

\subsection{Think ahead - Mental health}

Think ahead is focused on specialising in mental health and served to meet the needs of predominantly NHS Trusts and Local Authorities in England. The Think Ahead teaching programme provides a six-week residential teaching block that aims to prepare students for their practice placements, led by a Consultant Social Worker. In the first year, trainee students will receive a postgraduate diploma in social work; and go on to gain a Master's degree in social work.

The learning outcomes of the residential programme is intended to provide a grounding in approaches to specific theories for practice, mental health social work, learning to mental illness, its causes, and the legal and policy framework that are upheld in practice and an understanding of the knowledge and skills statements for adults implemented by the DfH (2015) - and aligned with step up and frontline programmes, for all applicants would be assessed against and to become familiar with the Professional Capabilities Framework (BASW, 2015) for social workers (entry level).

\subsection{The apprenticeship route}

In its' early stages of development, the newly developed three year apprenticeship route specifically states that training social work students will work in partnership with adults, children, carers and families and based in a range of different settings to carry 
out the duties and responsibilities required of the role. The access to this route is led by local authorities that will support new students over a three year period to meet the requirement to become a qualified social worker. The newly developed apprenticeship route specifically states that training social work students will work in partnership with adults, children, carers and families and based in a range of different settings to carry out the duties and responsibilities required of the role.

In respect to a professional skill set for the social work profession, the learning outcome intentions for this teaching programme refer to specific areas of knowledge relating to, person centred practice that informs assessment, care planning, and the management of complex situations. The need to understand the legal responsibilities and theoretical framework that inform understanding in respect protection from harm, abuse, neglect and exploitation. In order to apply this professional skill base, the importance of critical reflection and decision making abilities are emphasised (Skills for Care, 2018).

\subsection{Discussions}

\subsubsection{Epistemological position}

In recognition of my own potential bias, as the author and educator within a $\mathrm{HEI}$, it is very difficult to comprehend how fast track routes, in comparison to the HEl academic routes, could be seen as successful. The level of academic teaching time of the fast track routes have been significantly reduced in favour of work based learning opportunities that promote students working in different areas of practice. I.e. mental health and children services. The reduction in teaching time falls significantly short in comparison to the two and three year teaching programmes. I consider the promotion of a fast track route will exacerbate the concerns of the professional skill set of a qualifying social worker. The bewilderment is; the new programmes provide less time in teaching and strengthening the professional skill set of social workers that had been consistently criticised. Therefore, it is difficult to understand how social workers entering into the profession through the new routes of entrance will be better qualified and more equipped with a professional skill set to take on the challenges of social work. With the intentions to improve the outcomes for vulnerable people that the literature review had all voiced concerns about, it is a struggle to see how this can be achieved when social workers are being taught with new models. The models have changed the focus of learning to understanding process and operations rather that the 
opportunities to consider the breadth and depth of knowledge and skills afforded to a generic professional skill set.

The findings at this stage of the literature review is that the established educational social work model that provides a generic professional skill set in order to qualify and enter into the social work profession has been met with a strong political challenge. The government have responded to the recommendations of the reports and reviews and have initiated the development of new routes of entrance into the profession with local authorities taking the lead in their management with unclear visions of their impact. However, the concerns to be explored are in relation to the new routes of entrance possibly impacting on the teaching and assessments processes alongside the quality of the professional skill set of the profession, in favour of quantitative measured to meet workforce demand.

\subsubsection{Quality versus quantity}

The government have changed their funding plan to afford the social work profession. The intention of this shift, is to build the social work force that will respond to the crisis of recruitment that has become a major concern for local authorities within the social work profession. The new routes of entrance can also be seen as the introduction of specialised pathways into the profession. Whilst it is not the aims of this study, it must also be acknowledged that a significant attraction through the new routes of entrance is in respect to personal costs. Within the independent evaluation undertaken for the DoE in respect to Frontline and Step Up. it was recognised that "Step Up to Social Work allowed them to complete this by paying course fees and providing bursary that enabled them to continue to support their family and fund living costs" (DfE, 2016).

A DfE spokesperson supported the success and progression of the new routes of entrance and suggested Frontline was a "valued partner" in achieving its goal of "recruiting, retaining and developing the best social workers (Turner, 2019). This eludes to the DfE's agenda and business plan to meet the needs of the shortfall of resources for the profession in terms of recruitment and retention challenges that are a major cause of concern for local authorities. In February 2019, it was confirmed that a further $£ 45$ million pounds would be awarded to fund training programmes to develop a further 900 social workers through the Frontline teaching and access route (Community Care, 2019). This allocation of funds has endorsed the continuation of what is considered as cost effective routes of entrance into the profession although it 
needs to maintain a partner university for accreditation of the postgraduate awards (Community Care, 2016).

The response can be seen as positive in terms of addressing the issues of recruitment and retention that is being experienced within the social work profession. It could also be argued, based on the original evidence referred to, that the original $\mathrm{HEI}$ routes are not attuned to what is required in current statutory practice. Therefore, the decision to fund new routes of entrance into the profession and reduce the dependency on $\mathrm{HEI}$ undergraduate and master's programmes could be seen as a positive new start for social work training that is more aligned to understanding the multi cultural issues within the communities they live.

Therefore, whilst it is valued that more staff will be operational at the frontline of social work practice, it is questioned whether the new routes of entrance are compromising the professional skill set that is required in order to work in current modern-day practice. It must also be acknowledged at this stage; the predominance of this investment is focused upon children's services and not adult service which is at risk of dividing the social work profession and diluting its professional skill set.

\subsubsection{Regulations}

The undergraduate degree and the established Masters HEI routes of entrance into social work are regulated and validated generic programmes that are seen to have robust teaching and assessment processes aligned to the HCPC SoP's and PCF's. This study has recognised that the KSS for both children and adults can now also be seen as part of the assessment that informs the learning and qualifying process. However, the assessment framework and learning outcomes are not at a consistent standard across all routes of entrance into the profession. Therefore, it can be argued the assessment framework has resulted in a level of chaos and confusion in respect to learning outcomes of qualifying students, between the established and new routes of entrance who are working towards a different framework.

The inconsistency of the learning outcomes for qualifying social workers alongside the different models of teaching will inevitably result in an inequality of a professional skill set that is expected to inform the social work profession. With the addition of the introduction to the KSS and the fast developing regulatory body of SWE it can be seen that the profession has become ever more confused and inconsistent than before, in 
terms of its expected professional skill base for the profession. Therefore, it is acknowledged that the achievement of a comprehensive and relevant, robust and balanced social work education curriculum and the clarity of a diverse professional skill set, in the face of many and various influencing issues and forces is 'no easy task' (Burgess and Taylor, 2005, p.13) and will remain ambiguous for future practice.

\subsubsection{Education and epistemic injustice}

In comparison to the historic $\mathrm{HEl}$, teaching programmes it is recognised, the fast track routes of entrance into social work are reduced in terms of their academic teaching time in favour of specialised social work practice. This means qualifying social workers spend an increased level of time in practice and develop a predominant amount of their professional skill set through work-based learning. This will result in social workers who are very knowledgeable in the areas of applied practice but limited in their underpinning professional theoretical knowledge and skill set, as well as restricting their own career progression. Rawl's theory of distributive, epistemic justice and the principle of "social and economic inequalities" refers to characteristics such as values and opportunity within the context of fairness that are to be distributed equally (Rawls, 1971:62). Therefore, it could be argued the loss of knowledge that is afforded to the generic teaching programmes and not toward the fast track routes of entrance training programmes for newly qualifying social workers results in the provision of an unequal distribution of knowledge. However, without this disclosure, I argue that the reduction of knowledge and skills for qualifying social workers is an act of hermeneutical injustice. Participants in new programmes may not be aware that they are not being provided with the strong knowledge or a generic professional skill set in order to practice safely and meet the expectations of statutory social work practice. The impact also brings concern towards acts of further epistemic injustice for the vulnerable people served, to suggest we have a strong professionally skilled numerical workforce that was at a cost of weakening the knowledge and professional skill set of the statutory practitioner.

The Croisdale-Appleby report (2014) is supportive of the original value base of generic social work practice, that social work practitioners should possess a foundation of shared levels of knowledge, skills and capabilities that underpin professional practice - He goes on to challenge the recommendations and the new routes of entrance into the profession in support of educators. Croisdale-Appleby shared concerns that they 
would not address the issues of social workers becoming more equipped to practice upon qualifying. "will not offer opportunities for adequate internalisation of some of the major attributes knowledge, skills and capability of application in a sufficiently representative range of practice which educators feel newly qualified social workers should possess." BASW also argue that Frontline is a less "academically rigorous programme and undermines the traditional academic routes into the profession" (Community Care, 2019).

\subsubsection{Generic practice and specialised practice}

As the author of this study, and the commitment to generic practice, it is becoming increasingly concerning when completing the literature review, the main focus of social work practice development and expressions of concern have been heavily dominated by children services. This was motivated understandably by the motivations that followed to complete Inquiries and reviews due to tragedy and child death. However, this is to assume there have been no tragedies or issues of safeguarding, care and support which is as equally as important in adult services.

The Care Act 2014 clearly places safeguarding duties for adult services within the statutory adult social work teams in comparison to children services. Whilst it is widely recognised the challenges and importance of applied skills and knowledge within the practice of child protection, we must be equally be assured that social workers within adult services are valued and skilled in order to meet the demands of complex casework, safeguarding duties, and the necessary skills and knowledge required in order work with this service users group. It can be argued that a social worker deemed as qualified through specialised routes of entrance into the profession have not received sufficient levels of teaching and training within the generic fields of practice in order for them to carry out this work should they chose to change direction once qualified.

The loss of generic teaching and the separation of social work departments and services has resulted in a division of social services between children and adults. Children's services are being developed and clearly positioned within local authorities. However within adults social work the recent review - Chief Social Worker for Adults' annual report: 2018-2019 - social work leadership in changing times (Department of Health and Social Care, 2019) shares the commitment for adult social work in regard to the integration of health and care systems. 
Croisdale-Appleby (2014) recognised the importance of generic social work practice, which was highlighted due to the new routes of entrance becoming specialised focused. The changes of the implementation of the new models of training and the emphasis placed on children and child protection may detract from the important contribution social work makes to adults and mental health services. The added tension is that this assumes adult social workers do not work with children and families and children social workers do not work with adults and families. However, all the reviews and reports suggest, the consequences of the latter point is that qualified social workers will not have the necessary knowledge or experience of working within adult services and adult specialised social workers unable to practice within children services.

It could be argued therefore; those concerns of students being ill-equipped for practice have grown rather than abated due to the different models that have since been introduced as new routes of entrance to the profession. The new models of social work education are seen to prefer practice skills rather than provide a balance and focus on teaching and learning exercised through the traditional academic route. In relation to generic practice perhaps it is unrealistic to expect them to be knowledgeable in all areas of practice. The clear challenge for social work is the need to adhere to the neoliberalistic methods of the political agenda, and afford the professional development of the profession. The concerns identified relate to the compounding of teaching time for qualifying social workers in favour of developing a numerically stronger workforce, which is considered by academics to significantly impact on the professional skill set of the profession in the future. It would seem based on the outlines of each programme, the opportunities to be taught a strong theoretical underpinning of a professional skill set has been lost in favour of work-based learning. It is my view that the reduction in teaching will only exacerbate the concerns that had been previously experienced and expressed with the literature, rather than address and aim to improve the situation. Whilst a stronger workforce in terms of numeracy is considered a strength, I suggest that the future workforce has been weakened by the reduction in the quality of its professional skill set.

The focus on specialism and children services may look to improve the professional skill base of the practitioners but will impact on social workers pathways in the future. The implications of the limitations of their knowledge will increase the risk of social 
workers not being able to transfer their practice should they chose to change direction later within their careers. Practitioners who wish to work within adult services in the future and move from children services will be seen as not holding the necessary skills and knowledge to equip them to practice safely and equally vice versa, thus conceding to the possible separation the social work profession into two services. Therefore, whilst there is strength in specific areas of knowledge, the new routes of entrance are seen to potentially affect the generic knowledge base and the career possibilities for social workers.

\subsubsection{Practice based learning (PBL)}

Practice based Learning (PBL) has been argued to limit social work student potential and learning opportunities. It is considered students are able to understand and learn by being engaged in practice but restrictions are present in respect to the amount of deeper levels of learning and knowledge based informed practice if the teaching of knowledge and understanding are compromised (DeWalt and DeWalt, 2011). Academic teaching is seen to equip students to enter into the profession however, if their practice experience does not relate to their theoretical knowledge, students will rethink theories, or revisit theories to see if they can fit it into their own worldview.

The relationship between theory and practice can be seen as co-dependent (Beard \& Wilson, 2013). Major et al (2011) theorises students entering into work-based learning (WBL) are more equipped in their understanding of practice although acknowledged, students must be self-motivated towards independent learning, have the ability to discern learning at a deeper level, alongside the ongoing development of knowledge and understanding. However, time and specific placement orientation i.e. children and family services limit the potential for generic learning and offer more specialised models of learning (Wadel, 2015). Thompson (2015) also explores the dangers of social workers responses in practice that suggest; they don't tend to think about knowledge or theory and that they are seen as separate entities and expresses concern that inappropriate actions may be taken due to a failure to understand situations. He argues that practice cannot be disconnected from theory such as thoughts and ideas in attempts to understand or respond to differing situations.

It is the expectation of the educators to become gatekeepers of the profession and ensure the robust teaching frameworks are in place to assess the levels of abilities of the students. A robust programme which enable the profession to be guarded by 
academics and professionals of the profession itself. 20th century Educational Theorist, John Dewey, advocates for the philosophy and principles of experiential learning in Higher Education. Dewey, argued that experience doesn't always lead to learning if the model lacks purpose or organisation and emphasised learning as a process which integrates experience, concepts, observation and action (Kolb, 2015). Therefore, breaking away from historic norms of teaching, perhaps it shouldn't be assumed that practice based or work based learning is better or will result in more highly confident practitioners, just as it can't be assumed students entering into the profession through academic routes do not have the practice or expertise that will prevent them from being good practitioners. 


\section{Chapter 5}

Methodology

\subsection{The aim of primary qualitative research}

The key aim of this qualitative study is to ascertain the participant's views and experiences in regard to their educational route into the profession and what they consider in terms of a professional skill set is critical in order to work within statutory practice. The study was motivated by the commentary within the aforementioned literature that qualifying social worker are seen as is with a professional skill set in order to practice as a statutory social worker. The methodology to carry out the study will be through the adoption and application of an Interpretative phenomenological approach in order to encourage retrospective discussions with 12 qualified social workers from both adult and children services.

\subsection{Methodology}

In qualitative research, it is expected that the researcher considers their position particularly in terms of how they influence the research pathways (Milligan, 2014). The responsibility that is placed upon myself as a social worker and as an educator for the profession was fast becoming a burden. This is due to the notion that the work I have engaged in that spans across many years, may have possibly contributed to the failing of so many students, and ultimately organisations and vulnerable people that has been suggested by the commentators within the literature review. It is my view of the profession, that we are not failing. We are a strong workforce with a wealth of diverse knowledge, skills and qualities that make up this profession. I consider the diverse professional skill set and the values of social workers are firmly based within the profession. However, this professional skill set and values have been ferociously tested by the wider systems that have placed incredible, unprotected pressure on the profession and the practitioners.

The latter view opposes the recommendations of some of the commentators that have been seen to influence the negative views of the profession. The marginalisation position of the profession, has been determined by the view imposed by the commentators towards the profession who are placed in an unequal influential position of power. The feelings of failure in my duties and responsibilities that are imposed on me, I consider is as a result of testimonial injustice as a direct result of the imposed label of a failing profession awarded to the social work profession. The failing of the known unshared knowledge of the commentators and the suggestions made that 
social workers are ill-equipped to practice in current practice, has impacted on myself who is associated as part of the morals and identity of the social work profession. Therefore, the values that underpin the social work profession and the efforts towards social justice is considered imperative in order to challenge the acts of oppressive power that have been experienced alongside the acts of testimonial and hermeneutical injustice that have arisen out of my feeling oppressed.

The two outcomes of the methodology chosen is to ensure the adoption of methods that encourage social workers to speak freely about their views and learning experiences of becoming and practicing as a social worker is considered to be an empowering approach to enable their voices to be heard. The second outcome will be that the contributors to social work education such as local authorities, BASW and SWE will gain a greater understanding of what professional skill set social workers feel is needed to be prepared to practice within contemporary social work.

Within this study I intend to gain a deeper, insightful understanding that focused upon "the insider's point of view" (Padgett, 2016, p.16), referring to the social workers. The adoption of a transcendental phenomenological approach (Moustakas 1994 P. 56 cited Cresswell, 2014) was originally considered to carry out this research. This approach promotes the gathering of descriptive views and experiences of others. It emphasises the importance of "bracketing" which requires the setting aside of the authors own views and experiences as much as possible in order to gain a fresh perspective towards the phenomenon that is under investigation (Creswell, 2014). The aim is to gain a deeper meaning that captures the lived experience of the topics being explored (Teddlie and Tashakkori, 2009, P. 135) from other people. However, Creswell suggests, an author's knowledge, views and perspective could be seen as a strength and together views and problems can emerge, be confirmed and understood therefore, assuming data cannot be separate from the researchers own background or history (1998, P24). Therefore, it is considered that my background in social work practice and within the field of academia places me in a strong position to understand the context of the experiences that were anticipated to be shared. The strength of this position can also be considered beneficial when interpreting the participants' accounts of their views and experiences (Hockey, 1993). The latter is the preferred view of the author as it has proven at many different stages of this study that my knowledge and 
insight has been extremely helpful but equally it can bring a risk of biased views which need to be considered when it is realised.

\subsection{Purposive sampling}

The consideration of purposive sampling is an essential stage when planning to engage in research to ensure the best outcomes of the study (Mason 2002, cited in Ritchie and Lewis, 2010). The choice of population and particular characteristics of a selected group to complete the study will allow the exploration of central themes, or possible insightful discourse (Burgess, 1984), that aim to meet the studies objectives. Therefore, in order to focus the study and gather data, decisions in respect to an appropriate target group who could contribute to the study that had shared the same phenomena was required (Holloway and wheeler, 1996; Patton, 2002; Robson, 2002; Ritchie and Lewis, 2010). The importance of amounts in terms of numbers of participants who could be invited to participate in the study was also to be considered.

In order to make this decision, it is necessary to fully acknowledge the progression that is taking place within the educational routes of the profession, particularly over the past four years. The latter point, is seen as conducive to the current drive within the social work profession to recruit social work graduates from all routes of entrance who have successfully completed their ASYE position within local authorities. The ASYE programme has been in place for four years since the introduction of the new fast track routes of entrance into the profession and holds a high profile of consolidation and commitment to on-going learning for social work in practice within statutory settings. Therefore, it can be assumed the social workers employed by the local authority over the past four years will have completed or are engaged in completing their ASYE, and could be seen as strong candidates to ensure the currency of this study.

The issue of numbers, accessibility, location, the scope of the study and limitations of time are all necessary considerations that influenced the final decisions made in respect to population and sampling for this study. With an expected participation of the population amounting from a minimum of five to a maximum of 25 participants (Polkinghorne 1989, cited in Valle and Halling, 1989). In respect to anti- oppressive values, I advocated that participation was a free choice to whoever is invited and wished to become involved in the study. The implications for making this decision directly impacts on the possibility of numbers for the research itself. The hope and intention of the author was the recruitment process, aimed at approximately 50 social 
workers. It must be acknowledged the organisations are involved in this study are recovering from a disturbing Ofsted inspection within children services. When I was applying for ethical approval to complete the study, it was shared by the principal social workers that morale within the counties were low, permanent staff numbers are low, agency staff numbers are high and the pressure of responsibilities was concerning. However, the methodology and notion of interpretative phenomenological approach of the study to empower social workers and listen to their experiences was welcomed. The view and optimism were both seen positive, that the findings could be shared to the organisation as a whole and may inform the greater good of the profession.

The organisation chosen for the research was based on the understanding that they recruit social workers from several universities where the undergraduate, master's programmes and fast track routes are all in operation. In order to prevent any possible risk of marginalising of isolating social workers who had completed their training through fast track routes, a combined sampling approach was required to avoid any type of exclusion (O'Connor and Lewis, 1999). Therefore, it was decided to invite participants from all routes of entrance into the profession based within one local authority (Appendix One). A further key decision was made in terms of recruitment: I decided that irrespective of the literature being dominated by children's services, and children services had recruited a greater number of ASYE social workers compared to adult services, the regulatory and PCF encompass the whole social work profession. Therefore, I ensured the population for the study was drawn from both adult and children services. The rationale for this is, the fundamental professional skill set base is to be considered for the whole profession and not singular areas of practice although it will be the singular areas of practice that their perspectives will be drawn from. The eligibility to be invited was: all social workers who have been qualified for over one year and in the past four years of their social work training programmes; they have completed their ASYE and are practicing within local authority statutory services.

\subsection{Professional research ethics}

As a researcher, the process and agreement of an ethics committee and senior managers of the local authority was paramount for the promotion and success of this study to take place. Research is concerned with protecting the safety and interest of the participants and others who are or could be affected by the research (Hugman 2010). Therefore, for this study, ethical approval was sought from the University Ethics 
Committee and both children and adult services within another organisation. This ensured the study met with the standards and principles of the Economic \& Social Research Councils (ESRC) framework for research ethics. Key principal 's that were paramount to this study were; informed consent; privacy, anonymity; promoting honesty; avoiding deception; managing confidentiality except when danger ensues.

During the application process to the ethics committee and the organisation concerned, two of the key principles required specific attention: managing confidentiality and the exposure and management of safeguarding concerns. The importance of safeguarding was identified and a plan of action agreed should any disclosures be identified that brought significant levels of concern that required greater consideration outside of the study. It was agreed that any safeguarding concerns identified will be explored with the participant by the author and an agreed plan of action would ensue that aimed to support the participant. Therefore, informed consent was sought and a participation information sheet was provided (Appendix Two). The consent ensured the participants were, completely informed of the aims and objectives, the management of safeguarding issues and their right to withdraw at any point up to four weeks following the completion of the interview.

Prior to all the interviews taking place, the consent forms were revisited and verbalised directly with each participant. A further form was sent following the interviews to confirm and remind them of their rights and the intentions of the data study. (Appendix Three). Discussions of safe and private environments needed to take place, particularly due to the preference of the majority of the participants who had chosen to actively engage in a telephone interview rather than a one-one interview. Social workers are very familiar with the notion of anonymity and dilemma's that safeguarding issues can bring to an individual in practice and therefore this was not a difficult subject to plan and discuss. I can confirm that a concern was raised during the course of this study that required a greater depth of investigation by with the participant. The provision of further explanations provided by the participant secured the concerns that interventions had been made by the senior managers of the organisation to address the issue at the time of the incident happening.

\subsection{Methods}

Within my own practice as a social worker and as an academic, the adoption of models of semi structured interviews, based on the skills of a narrative and enquiry approach 
enables the application of empowerment towards the participants to share their stories and views on the topic of enquiry (Kreugar, 1998, p.13). I considered it was very important to build on my own strengths and skills of practice alongside the application of anti-discriminatory and anti-oppressive principles that embodies a "person-centred philosophy". (Dominelli, 1998, p.24 cited in McLaughlin, 2012) and is conducive to relationship-based practice. The skills and values of person centred and relationshipbased practice are conducive to qualitative methods and the selected models of working. This approach enabled me to communicate and engage with all professionals involved in the development and application of the study and its greater values of listening to stories or perspectives of their individual experience of any presenting situation. Interviews, telephone discussions and group meetings are all methods being seen to enhance the authors own professional skill set that enables the principles of relationship based social work effectively promote equality and work towards social justice. Therefore, the selected techniques for this study are one-one, semi structured face to face or telephone interviews (Appendix Four). The selected methods were also responsive to time constraints alongside the author and the participants supported availability of their employers (Borque and Fielder, 2003).

\subsection{Participation}

The Invitations to participate in the study were sent to a total of 50 qualified social workers, inclusive of adult and children services. 14 invitees responded to the invites that resulted in a final 12 participants being interviewed. Two of the potential participants were unable to participate due to ill health that had resulted in them being absent from work for considerable lengths of time. A period of 16 weeks was planned to complete the interviews. One of the 12 participants who had agreed to participate in the study was as a result of snowballing which is a term used as an approach in an attempt to engage others into the study (Ritchie and Lewis 2003, P.94) This is applied by asking participants who have completed the study, if they are able to identify others who may fit the criteria for the study.

The characteristics of the research were clear and it was considered snowballing could potentially increase the participation and data and was seen as a low risk of the study or author feeling compromised. However, there was a risk of a potential participant who would offer to engage for whom I had not received any ethical approval from their organisation. Whilst it is recognised that social workers can engage independently, 
there was a possible risk of disclosure of safeguarding issues and having no support systems in place for reporting and supporting the participant. I decided to go ahead and allow the participant to engage in the study. I clearly informed her that any matters arising of concern would be managed safely and respectfully with her in the planned and structured process that I had agreed with the organisation supporting the study.

The study interviewed twelve participants in total with the first two interviews completed as test cases. Overall, six participants completed face to face semistructures interviews and six were completed over the telephone. No interviews were electronically recorded, this was asked but through choice, all of the participants did not want to be recorded. Therefore, notes were taken throughout, their views and key points were summarised and verbally agreed with the participants. The notes were typed up and sent to the participants to ensure respect for their views without further interpretation. For confidentiality purposes, the transcripts' will not appear as an appendix within this study.

\subsection{Pilot Interviews}

The overall intentions of the interviews is to gain social workers views and experiences of their current practice and if they feel their educational route of entrance into the profession adequately prepared them with the necessary professional skill set to practice. The interviews were broken into five categories that were planned with an anticipated time plan for each distinct function which were "Opening, introductory, transitions, key and endings" (Kruegar, 1988, p.21).

Stage One - Opening - Welcome and agreements

Stage Two - Introductory - Demographic exploration

Stage Three - Transitions - The ASYE - Explore what they learned and experienced.

Stage Four - Key stage - The shared learning of their social work education

Explore the professional skills set of a social worker

Knowledge at qualifying level

Skills at qualifying level

Attributes at qualifying level

Identify any gaps in knowledge and skills 
Stage Five - Endings - Explore what changes they would like to see in education models for students of the future - What are their future Plans

Drawing on my own experiences, a decision to allocate times to each category was seen as a management tool in order to keep interviews focused and within the times agreed. Therefore, in terms of time planning for the interviews initially, all sections were averagely timed in order to ensure the majority of the could be spent on the main focus of the study. This decision of timing is made due to not all questions being equal in their relevance or content. (Krueger, 1988). Following two trial runs, 10 further formal interviews were completed for the study. The trials enabled an evaluation of the semi structured interview plans and the management of time when applying a phenomenological approach. One of the pilot interviews was completed face to face and the other via telephone. The following reflections of the pilot's demonstrate the generic experience and changes made on evaluation of these trials meeting with the official participants in order to test out the questions and time management.

\subsubsection{Stage One - Openings - Welcome and agreements}

The opening stage can be considered as good professional practice. This stage provided the opportunity to initiate a working relationship, ensure the safety and wellbeing of the participant and secure signed agreements. This stage also allowed opportunities to ensure participants were clear about the plans, intentions, and their right to stop and remove all agreements to participate at any stage, inclusive of and up to four weeks of the interview taking place. This stage was procedural so no further reference will be made within the study.

\subsubsection{Stage Two - Introductory stage - Demographic exploration} I asked demographic questions as part of the introductory stage to the interviews. On reflection it is was realised, the rationale behind this decision was more attuned to my own experiences of participating in studies rather than considering their worth at the time. This section was afforded very little time initially as I did not anticipate the relevant data that would be elicited. I considered it as good "warm up" activity which remained for the duration of the study. Therefore, it is with surprise that the findings, whilst initially not considered as important as other stages to the key stage, the findings have added value and insight to the study which are shared later in the study. 


\subsubsection{Stage Three- Transitions - The ASYE - Explore learning and experiences}

The transitions stage was an opportunity for the participants to reflect on their practice since qualifying. The logical link and common theme was; all participants had completed an ASYE therefore this became the main focus of the critical reflection for this stage of the discussions. The initial intentions were to offer between five and eight minutes on this question. However, it became obvious in test case one, that I had completely underestimated the time, importance and potential valuable data of this question. Therefore, it was necessary to reconsider the wording of the semi structured interviews and the relevancy of the questions being asked in order to ensure everyone was offered an opportunity to share their experiences in the time allocated.

\subsubsection{Stage Four - Key Stage - The professional skill set}

The key research questions for stage four was planned to offer the greatest time 15 minutes as it was seen to be the most relevant to the research study (Kruegar, 1988, p.25) However, as in stage three, I had completely underestimated and undervalued the sheer amount of experiences of the social worker since qualifying and entering into practice that they would draw upon. I considered it was impossible to gain qualitative data on so many potential unknown qualities of the selected subjects. I was originally overwhelmed with the narrative and the challenge of recording the data that was supposed to capture the lived experience. To ask so many questions in such a short space of time brought the qualitative process and data of the research to be at risk of being lost and was therefore was adjusted. The reduction and re-focus of questions was designed to ask a reduced amount of open-ended questions, promote a narrative approach and with probing, follow up their responses in order to gain a deeper level of insight and understanding to the participants experiences (Ryan et al 2009, Denscombe 2014).

\subsubsection{Endings - Stage Five - Professional development and future plans}

To encourage participants to reflect and bring closure to discussions. The final ending question was intended to be positive and motivational in its approach with the notion of success for the ongoing professional development of the participants. Social workers are trained to be critical reflective practitioners. The use of various reflective models are applied in practice, dependent on the preference and preferred learning styles of the practitioner. Gibbs model (1998) had been applied in order to capture feelings, experiences and reflective accounts of the practitioner. The reflective model encourages the participants to consider their practice and focus on what they have 
learned through analysis what would they do differently in the future. Therefore, the ending stage was approached with two questions: how would the participants like their training to improve should they do it all over again? Secondly, in terms of the issues that have been identified within the study of recruitment and retention, it was considered by the author to explore what the participants were considering for their future in their careers.

In regard to the following two chapters of this study, stage two, three, and four are considered high levels of priority that provided strong data to inform discussions that respond to the focus of this study with a brief acknowledgement and commentary made towards stage one and five. The data gathered in stage one and five are important but due to the limitations of for this stage of the study, no analysis will be made at this time. 


\section{Chapter 6 \\ Stage Two and Three - Data Analysis and Discussion}

\subsection{Data analysis}

A thematic analysis was used for transcribing, instigating codes and completing the search for general themes within the data. Through labelling and discussion, extracts have been elicited for final analysis that relate back to the original question and literature (Braun and Clarke, 2006). Cross section and non cross sectional code and retrieve methods (Mason, 2002) were applied to the data alongside cross referencing systems (Ritchie and Lewis, 2003, p. 203) in an attempt to bring a systematic overview to the scope of the study. This action also led to the development of more abstract and theoretical emerging themes and concepts within the data findings that are later discussed (Strauss and Corbin, 1998). The transcripts have all been anonymised and the data confirmed by the participants. The participants are referred to as P1 - P14 for anonymity preservation and reference.

\subsection{Introductory stage - Stage Two - Demographics}

The introductory stage of the interviews drew out demographic detail that offers an understanding of the diversity of the contributors for the study. (Appendix Five) Out of the 14 potential interviews, 12 were completed, eight participants were from children services in different teams such as; referral and assessment, long term safeguarding and fostering and adoption teams. Four of the participants were all from adult safeguarding teams and two participants did not complete the study but their numbers were not removed from study to avoid confusion. In terms of diversity for the study, all the participants were female, ageing from twenty-two - forty-nine years. It is unknown if any men or non-gendered identified participants of the original number of 50 participants would have been invited to participate in the study. Two participants were of mixed race and all others referred to themselves as white British. Six participants completed an undergraduate programme, one through a postgraduate route, one through step up to social work and two through a Masters route. Four different universities were involved in the teaching of the participants and only one participant moved to complete their qualifying programme. All participants have qualified and completed their ASYE between the years 2015 and 2018.

\subsubsection{Summary}

The importance of this data is whilst the group is small the participants involved did bring a respectful level of diversity with the views and experiences shared, due to their 
own biographies and also their attendance at different universities which will have resulted in teaching and learning experiences alongside age differentials that enhanced the study.

In terms of entry Levels and eligibility, whilst this has not been a key focus of this study, the findings are informative in respect to the different starting positions all the participants had achieved in order to enter into the social work profession. For the undergraduate programme's participant $\mathrm{P} 14$ had entered on completing her $\mathrm{A}$ levels when finishing school. Participant's P1, P2, P3, P5, P8, had entered with work experience and sufficient qualifications to meet the eligibility criteria to train and enter through an access route. This means they had completed a one- or two-year college programme to meet the eligibility criteria to apply and train as a social worker. For the master's route both participant's P4 and P9 had completed a degree, one achieving a 2.1 and the second participant, a first in a subject considered relevant to the profession. Participant P12 was accepted to her master's programme with a 2.2 degree and good practice experience. For the step-up programme P13 had a 2.1 degree. The eligibility criteria into the social work profession has not been considered within this study but the data reflects the variables that exist between the different programmes that promote inclusion.

\subsection{Stage Three - Transitions}

The experiences and views shared within the transitions stage enabled the identification of three common themes, referred to as positive and challenging outcomes (Appendix Six). The three themes with conflicting outcomes from both a positive and challenging perspective for the participants can be seen as: placements becoming the platform for their progression; management and leadership to meet with the ASYE requirements; the continuum of learning to enhance the developing professional skill set of a social worker.

\subsubsection{Placements}

Participant's; P's 1, 4, 8, 9, 13; had all completed a generic programme except for participant $\mathrm{P} 14$, who had completed a specialised route of entrance into social work. The final area of practice, albeit children or adults became the area of practice to complete their ASYE with some entering into new teams but was considered a platform that equipped them to entering as a qualified social worker. In comparison, it was found that participant's $P 2,3,5, \& 12$ all completed their final placements in 
subject areas or teams that they did not continue to practice in. The data findings identified that they felt they had not been provided with the opportunities that could have helped them when entering into practice.

In comparison to the latter group, the first group within their final year placement experiences are seen as positive and that the placements from which they had progressed was considered advantageous for their career path and strengthening the required professional skill set in readiness for the ASYE.

Participant P1; "I completed my ASYE in the team where I was based for my final placement, it really set me up, as I had gathered a good level of knowledge before starting my ASYE":

This was comparable to the work-based learning experience of $\mathrm{P} 13$, who had completed the singular step up route of entrance into the profession.

Participant P13; "for me, it was the best route because I wanted to work with children".

Participant P8, felt accomplished on qualifying and the transition to ASYE seemingly seamless.

Participant P8; "Yes, I was really lucky, my 3rd year placement was in the assessment team, this meant a lot, it was great foundation to the start of my career and in respect to the commitment to the continuum of learning, I understood my knowledge and I had a personal development plan":

However, for the latter group experiences were not seen as successful.

Participant P2; "I liked working in adults but the lecturers suggested that I should do children and get this area of practice under my belt first":

Participant P3; "when I qualified - in my final year, I wanted to go into child protection. Everyone was pushing for children and this was encouraged by the lecturers, nearly all of them came from children services":

Participant P5; "I wanted to work in mental health but they had had a massive reorganisation so there was no placement or jobs": 
What has been found within this data, is that placements were incredibly valuable in terms of becoming a platform for learning in terms of practice based learning, particularly in regard to policies, procedures. This working knowledge was considered to have brought an increased level of confidence and being ready to practice as a qualified social worker. The findings with some of commentary from the latter participants was that they had been influenced by the views of the tutors or their opportunities limited due to the availability of placements within areas of preferred practice on qualifying.

\subsubsection{Leadership and management}

The success of ASYE programmes identified a theme relating to leadership, particularly in regard to the value of support and guidance provided to the participants which was seen as key to their success. Participant P2, expressed;

"I was protected, received extra support and supervision was good":

However, Participant's P1, 2, 3, 4, 5, 9, 12, 13 \& 14 all shared their views in respect to the challenge and amount of work the ASYE demanded some examples are;

Participant P2; "it was really busy, stressful, emotional, difficult, tiring, it's a learning process":

Participant P5; "the stress has taken its toll on me":

Participant P5 also shared her view and experience relating to the lack of support, the team dynamics and poor leadership resulting in;

"the process is hard, unfair and unbalanced, it was really tough at times and I wanted to go back to my old job. I feel that I am resilient but even with my resilience, I wanted to quit. They made me doubt my abilities. I had amazing support when I was training; it felt like a loss and bereavement and not social work value based at all":

Participant P9; shared her lack of support and guidance;

"My ASYE was horrendous. It's really sad when others have praised their ASYE. A really good manager is needed, if you don't have this, it's awful. I had amazing support when I was training. I was totally overwhelmed". 
Participant P12 commented;

" I have worked really hard on my ASYE. I felt like I was starting at the beginning again and in a place, I had never practiced. I just didn't realise how hard it was going to be":

In regard to earlier commentary towards the assessment framework for social workers, the concerns shared were validated.

Participant P1; "the ASYE had to be linked to the statement of knowledge and skills as well as the PCF's and SoP's which was ridiculous":

\subsubsection{Professional skill set}

In respect to the professional skill set, the positive outcomes suggest that almost every participant benefitted from their educational route of entrance into practice. Whilst the majority of the participants did not have a positive experience of completing the ASYE, they were all familiar with the notion of a continuum of learning required to develop the professional skill set of a social worker. The expectations and the responsibility for their need to obtain and remain engaged in learning, seek new knowledge and research was evident but allowing them to move into more specialised areas of their knowledge.

Participant P2; "My practice knowledge has improved 10-fold". I needed time and confidence. This was critical to improve my skills":

Participant P3; "My knowledge has improved but it's a gradual development as are skills". What the ASYE was good for was the reality of applying law and learning how to use it":

\subsection{Discussion and conclusion}

The findings within this stage of study in respect to: the positive outcomes relating to placement learning opportunities that developed into a permanent post on qualification; the consolidation of practice within the teams they had been based in their final year that contributed to the building of confidence: the challenging outcomes of themes identified, that were collectively expressed by the participants related to: the negative experiences of leadership and management; unrealistic demands of the ASYE programme; lack of support within the teams to complete the ASYE; the lack of clarity expected that related to the learning outcomes required to complete the ASYE: P2, P5, P9, all shared their views and experiences that the lack of support and 
guidance and amount of work was considered contributory towards increasing their stress levels. The negative experiences impacted on them completing their ASYE. The expressions of concern related to not feeling safe and a fear of being held accountable for their own poor practices that could result in vulnerable people being harmed or die.

P9; "I worked in a team that had a mentality of bullying and I was so scared. There was poor decision making. I thought a child would die if I didn't get the support I needed. I had to go the senior managers to make sure someone listened":

Both P5 and P 12 felt the amount of support that was being shared with others in different teams raised feelings of unfairness and unequal power imbalances within the organisation. P5, and P9, felt the standards of practice due to poor leadership resulted in concerns for their own health, wellbeing and a possible risk that they may not pass or complete the ASYE.

These findings have identified concerns of unequal levels of support and guidance being provided to social workers by their managers of the service. The levels of concern shared related to risk of neglectful practice that could ultimately result in harm or death. In this instance the participant advocates the critical knowledge required as part of a qualifying social workers professional skill set is to have awareness of the organisational responsibilities and leadership in order to address such concerns if they arise without consequence.

The ASYE programme relates to practice experience that aims to be influential and supportive towards the consolidation and a continuum of learning for qualified social workers. The advantages of being in practice and having the time and support to learn how to manoeuvre through the complex systems, process, apply theories, practice informed aspects of law and develop practice wisdom, through increasing levels of experience was considered invaluable for most.

Further findings in this stage of the study related to the demands of the ASYE and the subject element of the taught programme. In terms of demands, this was particularly relevant in terms of the time allocated to complete the number of tasks and written reflection for the ASYE. In regard to the taught element of the programme, this wasn't considered helpful with some of the participants. The teaching was seen as a repetitive 
programme of teaching that had been completed on their qualifying routes rather than supportive of their progressive learning.

In regard to the professional skill set of a social worker, the high dependence of good the leadership and management was highlighted as critical to the success of participating staff completing an ASYE. However, if this level of competence is not executed that ensures support and positive learning experiences it is critical that a qualified social worker is able to: voice concerns; know how to manage and overcome issues of power; the abilty to be confident in applying these qualities.

The findings and views of the participants are both encouraging and concerning. However, it must be acknowledged, in respect to the concerns shared, the ASYE and its findings was never the intention of this study. However, in order to bring balance and fairness the findings have identified that this study would have benefitted from a broader view and aimed to involve leaders and managers in the study. Their contribution would have brought a balance in terms of understanding their views and experiences. The contribution of managers may have helped towards ascertaining their views and experiences in respect to; the challenges of managing and leading services as a result of the budget restrictions and the concerns expressed relating to the professional skill set of the profession.

Stage three of the research was only ever intended as the transitions stage. The findings have identified the importance of leadership to support the continuum of learning that ultimately aims to deliver qualitative social work practice. However, the data has raised several questions that would be worthy of exploring further that are beyond the remit of this study. The outcomes have identified: the recognition that the taught route of entrance plays an important role and final placements, to ensure a foundational base of knowledge and practice that informs social work practice and the concept of the continuum of learning; the value of understanding of how one learns has been considered but based on the shared evidence, its success is dependent on the importance of having a supportive team and manager to ensure the success and engagement of an ASYE candidate; that managers are leaders of ASYE programmes are engaged into a learning culture. 


\section{Chapter 7}

\subsection{Introduction}

\section{Stage Four - Key Stage - Data Findings and Analysis}

This stage has been split into four topic areas: to identify the collective view of a professional skill set of the participants; theory and practice based learning; statutory practice versus relationship based practice; leadership and management; the concerns of epistemic injustice: the identification of these themes were drawn from the application of a colour coded thematic analyses that was used to breakdown the areas of experiences, and views identified (May, 2001, p. 193). The themes were cross coded with further abstracts identified during the analysis process and broken down into topic themes that were deemed critical by the participants.

The experiences and views shared enabled the identification of common themes, referred to as Taught Knowledge - Applied Knowledge and Critical Knowledge. The key themes were determined due to the frequency in which the subject was raised and used as a means to identify it's characteristics (May, 2001, p. 191), critical knowledge was then broken down further and cross referenced under the headings relating to the earlier mentioned PCF framework. The participants also shared perspectives that have brought abstract findings that have been recorded and will be briefly referred to (Appendix Seven).

\subsection{The professional skill set}

Through interpretation within the participant's narratives, the findings were dependent on their learning experiences, their value base of social work, their statutory duties and the commitment to a continuum of learning. Whilst the main focus of this discussion refers to the professional skill set, it is important to acknowledge at the stage of qualifying every participant felt they were equipped in terms of a varying, diverse and personally owned professional skill set to enter into practice. All participants valued their learning, irrespective of their personal experiences. On reflection, all were able to appreciate what they had been taught but expressed initial difficulty with detailed recall. When a deeper level of enquiry was applied that attempted to determine specific areas of taught knowledge, most participants struggled to recall any of the knowledge types, law and theories that related to the university aspect of their teaching. However, in applied knowledge, they were far more explicit but referred to theories that they use rather than what they know but the value of knowing them was important. 
Participant P8; "you don't use all the theories but you need to practice to know them and for them to make sense":

It was found within the findings, in respect to the professional skill set, a strong list of knowledge, skills, values and characteristics have been described but is not exhaustive. In regard to knowledge and skills albeit it taught and applied. It can be seen in appendix that the participants provided much more clarity of their knowledge and skills when they reflected applied practice rather than refer to academic taught knowledge. However, whilst it would prove difficult and is not the intention of this study to literally determine knowledge and skills and how they are taught, we can see that the interdependency has resulted in a broad and credible balance of knowledge and skills to inform practice that has been drawn from five different universities and access routes.

This consideration of a personal and professional skill set allowed for the identification of themes that were considered critical for modern day generic statutory practice: skills of verbally communicating at all levels of operations; sensitive to diversity was required in practice; the time consuming challenge of writing a plethora of complex and differing reports and plans required within statutory practice; the ability to draw on a strong knowledge base that related to law, psychological and sociological theories; applying relationship based practice:

The Croisdale-Appleby (2014) social work education review explored the "characteristics of abilities" with definition for a social worker as being seen to need to be able to hold resilience; skills of communication; capability to undertake holistic, risk and evidence based assessments; decision making process relating to priorities of resource allocation; determining interventions; multi professional working; effective communication; effective scientific methods; models of multi professional working are adopted in practice; reflective skills; the application of ethical and legal principle's respond to the protection and safeguarding powers and duties; seek to further understand social work through evidence gathering and research.

All these characteristics have helped to define a set of expected professional skill set, to include different abilities and levels of communication for the profession that are built upon as practice expertise is gained. Barth, et al (2013) refer to the 'common elements' approach" in social work and argue, all social workers need a body of 
knowledge and skills that are wide based and generic and applied across a wide range of practice contexts. In the context of education, the characteristics of abilities referred to by Croisdale-Appleby, are subjects relating to skills and knowledge that are qualifying students are educated and assessed through taught and practice learning models. Therefore, in comparison to the findings of the study, whilst some of the characteristics were seen as critical by the participants, the evidence to support the absence of such characteristics was not identified.

\subsection{Theory versus practice based learning}

In reference to earlier commentary, the views and experiences of education and preferred methods of learning was shared by participants within their commentaries. An observation when completing this stage of the research was the difference by participants when sharing their reflective accounts on taught areas of knowledge and skills against the placement and applied practice but realising the need for both aspects to learn.

Participant $P 1$, I am strong on theories, I was taught law but it was when I had to understand in detail and apply it in placement was when it all made sense".

Akin to the data identified within stage two, what would be seem is the strength of the taught element of social work education that was supported by work based learning that could be tested out. It was also found that learning in practice brought strengths and struggles to practitioners.

Participant P14; " I feel I learned so much when I went into placement and since I have been qualified. I learn better when I am doing the job. Because of my placement and my job, I understand what I am doing and why. I had good teaching, you need your theories but you have to have experience and try to apply them so they make sense":

In regard to struggles participant P12 expressed her struggles with trying to manage and understand systems and processes.

Participant P12; "It is the case of understanding the systems that I struggled with, they are so complicated" and dependency on the management and leadership of the team in which they were based: 
This small sample of the views and experiences of social workers shared their preferences and learning needs in regard to how they learn. However, what was identified as theme related to the need to understand and have a strong knowledge base but the need to be able to apply this knowledge in order for it to make sense highlighting the value an importance of practice and work based learning.

\subsection{Relationship-based practice and statutory duties}

In reference to earlier discussions that related to the Munro report (2010), concerns were shared by Munro of the relationship-based values of social work that had been compromised in favour of responding system and process driven methods of working. It can be seen within the data that the intentions and importance of relationship-based practice was referred to by participants.

Participant P2; "Relationship based practice, working with diversity and personcentred practice are critical. You must be able to adapt your approach to ensure the service user and carers are centre":

Participant P5; "Relationship based practice and unconditional positive regard are so important. You have to build a relationship and you have to find the balance between this and the duties that you are trying to stop situations getting worse":

Participant P9; "I think relationship-based practice is important although the buzz word now is restorative practice":

According to some of the views, the struggles arise with relationship-based practice when the severity of cases have caused greater needs of legal interventions that effect the dynamics of the working relationship with vulnerable people. In terms of knowledge, this discussion identified the importance of law. The knowledge of legal frameworks and how to implement the policies and procedures informed by law was expressed as critical to the professional skill base of a qualifying social worker:

Participant P1; "Law, you need to understand law for practice and this needs to have more emphasis at university. We were taught it but I didn't really understand because I had no idea how to apply it": 
Participant P4; "Relationship based practice, Maslow and strengths-based practice are all important but I am not sure we really use them in practice. It's all about law"

Participant P8; "You need knowledge of law and keep it current".

Participant P9; "Legislation, I didn't know anything, I can't even remember what I was taught at uni. The placement was the most important. I only learned through the placements and then just through working and learning":

Participant P12; Law is absolutely critical. You almost need a degree in law to do this work. You have to know what you are doing":

The understanding and application of law and duties was critical to the professional skill base of a qualifying social worker. It was expressed by the participants that it supersedes the need to understand the overall intentions of relationship-based practice within statutory practice. The original concern of a social workers ability to carry out statutory tasks and apply relationship-based approach to practice was not found in this study. However, the challenge to apply this approach was found to be as a result of the time that is afforded to carrying legal duties. The time and resources used to meet the demands off high profile situations demanding the attention of social workers have reduced the possibilities of preventative methods of working. The social workers and the profession are therefore currently caught up in a vicious circle. The main duties within their practice was seen to be responding to the need for legal interventions and the defensible overwhelming amount of administration required.

In terms of a professional skill base to undertake professional practice. It was found within the study, irrespective of their different learning experiences, the participants did not consider they were ill-equipped or inadequately prepared to enter into social work. The findings related to the struggle to balancing the demands of both relationship-based practice and statutory duties when working under pressure. Therefore, they were concerned with the amount of work and the wider issues of staffing and resources that has been highlighted as a main concern, rather than the questioned professional skill set of a social worker.

However, whilst the participants shared their feelings that they felt equipped to practice, the notion and expected learning outcomes of a generic programme to 
accommodate this was not reflected within the overall data of the study. Participant's $\mathrm{P} 1, \mathrm{P} 2, \mathrm{P} 3, \mathrm{P} 12$ and P13, all expressed concerns relating to the lack of generic teaching. It was viewed that the teaching and practice learning was mainly dedicated to children's services and the teaching relating to adults was poor with even less placement learning opportunities. The findings in relation to the teaching and learning experiences was the re-occurring theme that adult social work and safeguarding was not considered as important or held an equal position on the educational routes of entrance into the social work profession.

Participant P3; "both my placements were in children services. I didn't mind having two placements in children's, I don't feel I really missed out on adults, we didn't even have a lot of teaching on adults":

Participant P13; explained her only experience of knowledge and practice with adults was to visit different services over the course for six days. The value of any learning and accountability of these visits were not monitored or considered necessary for the overall assessment of learning.

\subsection{Leadership and management}

A further area of struggle identified within the profession related to leadership and management. The aforementioned concerns fully relate to the different levels of management within the profession and the impact they have on the practices of social workers. The position of responsibility and guidance is increased and they are also guided and influenced by government. Therefore, if the notion of returning to the historically valued and applied method of relationship-based practice is argued as a preferred method of working within the social work profession, then it needs to be placed at the forefront of all social work statutory practice. However, this will require fundamental changes in order to work towards addressing the crisis occurring within the profession and their struggle to stop the increasing demand of legal interventions. The role of government and their affordability to the profession would need to be challenged. The mindset of the profession needs to be prepared and encouraged to change and promote creative, preventative practices with statutory social work that aim to reduce the risk of cases escalating that result in law enforced statutory social work. 


\subsection{Social work knowledge}

The literature review identified key concerns derived from the reports and reviews that social work students emerging from the historic HEI routes were leaving without the necessary professional skill set that equip them to promote relationship-based practice and ensure efficient safe outcomes for people. The question arose; what knowledge, skills and qualities will define a competent and confident social worker in practice? Drawn from the aforementioned literature is can be seen the social work profession has an historic and fundamental expectation that a wide-ranging body of knowledge and core skills are a pre-requisite to qualify and enter into the social work profession.

Currently, social workers are expected to be trained and prepared to carry out their duties and responsibilities and respond to the demands of a diverse population within the communities in which they are situated. The earlier mentioned SoP's, PCF and KSS statements provide an assessment framework that refers to a body of knowledge and skills placed within a professional framework in which the student is assessed upon at each stage of their professional development. The assessment is part of, what has become a complex matrix, as it incorporates the SoP's (HCPC, 2013) the PCF's (BASW, 2012) and the later introduction in 2014 of two independent KSS statements for both children and adult services.

Considering the legal and professional duties and responsibilities of social work. The social work profession requires a professional skill set that is adaptable to change that meets with legislation, social policy and procedures of local authorities to ensure best practice. Dr Ray Jones (2017) also endorses the need for the practitioners to hold a depth of knowledge, insight and understanding of the realities, impact and possible outcomes that such increasing challenges bring to families and the environments in which they live. Within his writing of poverty and deprivation he refers to social workers being expected to respond to "barriers, inequalities and injustices" and the need for social workers to be "knowledgeable, reflective, ethically accountable and professionally competent". Jones goes onto discuss, social work practitioners being able to draw from a body of techniques, knowledge and skills that are conducive to a holistic focus and practice on individuals and their environments (Jones, 2017).

Thompson (2015 p.61) discusses the impossibility of clearly defining the levels and typology of knowledge required to be a social worker and the specific knowledge spectrums that allow practitioners to be responsive to diversity rather than be confined 
to mechanical and probable ineffective ways of working. Thompson goes on to explain the reasoning for its complexity is due to knowledge base of social work emerging as a result of practice, theory, policy and research alongside social and political circumstances that bring inevitable change.

This suggests without definition, there is a need for a vast and varying knowledge base that will enable a social work to respond generically to all service user groups, inclusive of children and families, adults, older people, and mental health services. Within Munro 's research, it was found, social workers based in statutory settings had become very concerned with complying with procedures and regulations, exposing "a bureaucratic, top down, directive, managerial approach", (Munro 2011). Therefore, it is suggested that the mechanised practices are taking priority to support the political business models that demand accountability and high performance and outcomes. It is considered that the values and principles of relationship-based practice of the profession are at risk of disappearing from statutory social work practice. The mechanised model can be seen as an obstruction to relationship-based practice which in contrast promotes the values of the social work profession. It is the expectation of the social work profession to be creative and diverse and adopt the values of the relationship based social work practice and a bottom up approach to practice.

\subsection{Social work skills}

Similarly to knowledge, it is considered an expectation to have a professional skill set that informs the applied duties of statutory practice of a social worker and is responsive to relationship based practice, diversity and the challenges that political and societal changes can bring to individuals and families. The knowledge base of social work needs to be reinforced with the application of a specific set of skills, that are heterogeneous, and responsive to the political, cultural, and individual changing demands of the community in which social workers practice.

Munro expressed her concern that as a direct result of a "top down" approach, the professional skill and value of relationship based social work practice had been ground down in social work. Andy McNicoll (2016) reflects on the political climate and media intrusion that exposed the difficulties of the baby $\mathrm{P}$ case into the public arena. Sharon Shoesmith (Director of Children service Haringey) became victim of the baby Peter case, as she was removed from her post and was held accountable for the poor practices within the Haringey local Authority, alongside other social workers who were 
all eventually dismissed. McNicoll discussed "A climate of fear" in the aftermath of these responses that seized social workers across the country, alongside a cascade of child protection referrals and children being taken into care. This perspective fully endorsed the original expectations and findings by Eileen Munro, that systems and processes had taken priority over good relationship-based applications.

Pamela Trevithick's writings of knowledge, skills and values and relationship based social work in practice has been enormously influential within the social work profession. Trevithick (2000) attempted to define through case discussions to demonstrate particular skills relevant within social work practice. Trevithick's work would promote the value of a "lexicon of 80 skills and interventions" (Martin and Hollows, 2016) being applied in all areas of generic practice. Trevithick (2003), also explored past writings on the social worker-client relationship and advocates the relationship base of practice is central to effectiveness and good practice. (Trevithick, 2003, p. 163-176). The value of service users should be at the heart of social work and should be at the centre of practice. A value reflected within Munro's report of children's services of which she considered relationship-based practice had been compromised.

The challenges for social work as a direct result of outcome focused practice relate to: the day-to-day basis of social workers responding to bureaucratic trends that result in their workload being disproportionate: it was found within the study that the area students felt under prepared for was the reality of the copious amounts of writing and time seen needed to complete the different reports and case notes required; the insurance that systems and processes are followed rather than having the time afforded to carryout direct face to face relationship based social work practice (Hingley-Jones and Ruch, 2016).

\subsection{Social work qualities}

The term qualities has been used throughout the study based on the works of Trevithick who used the term in her early writing. The term qualities is defined within the Oxford English Dictionary (2019) as "The standard of something as measured against other things of a similar kind; the degree of excellence of something". (Oxford dictionary) with synonyms such as calibre, characteristics, attributes and values, that have all been used within the literature review but to suggest the social workers lacked these qualities. 
Within the social work profession, the concept of diversity, referring to respect and understanding is that each individual is considered unique, and we acknowledge our own individual differences in comparison to each other. This can be along the dimensions of race, ethnicity, gender, sexual orientation, socio-economic status, age, physical abilities, religious beliefs, political beliefs, or other ideologies (Thompson, 2015). They are developed through birth right, culture, life experience, practice, and education, research, taught skills, research and observations of others. Therefore, the experiences, perception, understanding, ownership and application of these qualities that unite with knowledge and skills to develop a professional skill set are generic and personalised. This is the undefined richness of the qualities within a professional skill set that is expected within the social work force.

\subsection{Epistemic Injustice and the distribution of power}

An incongruence has been identified within the study in respect to the relationship between the government's position of power and the descending layers of power and responsibly that cascades throughout the bureaucratic levels of management within the social work profession. The immense challenge for the government to protect the public in regard to care and safeguarding with its heavy and undefined responsibilities have been clearly expressed. The concerns of epistemic and hermeneutical injustice in terms of prejudice and scarcity of resources and how this has impacted on the social work profession and the practice of social workers have also been considered. However, the primary study has identified acts of epistemic injustice in respect to the distribution of unequal, influential power towards social workers within the institutions of the social work profession. The findings of the study identified leadership and management as a theme that was consistently highlighted and seen as a major contributory factor to the success or possible destruction of the aforementioned expectations of the practitioner working within the social work profession. Therefore, the need to consider descending powers and the influence of middle management is seen as a critical discovery that is worthy of comment but is in need of further research as it was not part of the original intentions of this study.

The importance of understanding power, professional responsibility, professional practice, professional identity, and conduct has been highlighted as themes that are worthy of attention for this study. In practice the aforementioned characteristics are considered a critical area of knowledge and understanding in terms of its 
comprehension and application and can be seen as fundamental in terms of the standards and expectations of social work practice. Phenomenological approaches focus on the position of the individuals and their interpreted view of the organisations they are based. Its key concern is in regard to relationships with groups and individuals. The relationship of leadership and management has been identified as critical to the success and positive experiences for qualifying social workers in training and applied practice. Conversely, it is also seen as a major contributory factor for the challenges and negative experiences of learning and development and applied practice that some of the participants experienced. In respect to epistemic and hermeneutical injustice and the unequal distribution of power, the power relationship between a social worker and their leaders in regard to the support and a learning culture of their university can deeply impact on the well-being, potential success and future career plans of a social work student.

At this stage of the study it can be assumed that the social work training teaching programmes are underpinned by the social work values of the profession and its infrastructure designed by its regulating body. Irrespective of the earlier discussions of the conflicts of the changes to the educational routes of the profession and the organisational bodies that have developed the infrastructure it is also to be assumed at this stage that the aforementioned diverse professional skill set is a pre-requisite for qualifying practice. The values and professional skill set enables the application of guidance, both consciously and unconsciously in social work, professional development and practice. (Hodgkinson 1991 cited in Busher, 2006, p.70) There is also an assumption under this influence that a professional identity or self-identify will be constructed (Busher 2006). However, the power relationship between the organisations involved in the contribution to learning and development of students and the distribution of duties and services of local authorities that are tasks carried out by social workers have been brought into question. The data and narratives share the complex and challenging areas of management, the application of power, bureaucracy and leadership.

The dynamics of power emerged from the study, particularly in relation to diverging powers of support and influence. The fluidity of power is also validated and exposed and reflected on by the participants relating to their practice experience and decision making for their future, applied practice and the continuum of learning within the social 
work departments and teams. However, the levels of power, relating to how it flows amongst the structural, cultural, political or personal discourse (Busher, 2006) can also be seen within the data gathered as having had an almost indistinguishable but major impact that effected each participant at differing points, varying levels and episodes of time during their social work careers.

To conclude, within the data, a mixed response can be seen with all participants referring to how they were influenced, effected, supported or felt disempowered by their tutors, placement learning teams and the social work team leaders and managers of the placements in which social workers were appointed on qualifying. It is through some of the latter experiences within this study that a level of concern in respect to duties and standards of social work practice was brought into question. It must be acknowledged that this study was not afforded the time or capacity to work and meet with supervisors who provided the support and on-going practice through ASYE routes. This is an area of research that will possibly be pursued as the research develops in order to gain a broader and more balanced view of these situations.

The concerns raised relate to the possible high risk of social workers ultimately failing in their duties for the protection of vulnerable people as a result of poor leadership and the issue of inequality in support and guidance for practitioners. Social workers positioned within statutory services, at whatever level they practice will be based within a hierarchical organisation that will develop a work or professional related identity (Busher 2002, 2006). It is perceived that during the construction period of identity a persona is created allowing individuals attempt to move without discomfort from one community to another or mobilise between sites of "policy processes" (Bowe et al 1992 cited in Busher, 2002, p 68.) that are sustained by incongruous transactional relationships of power. 


\section{Chapter 8}

\section{Conclusion}

\subsection{Introduction}

The reason to complete this qualitative study was motivated as a response to the negative views that had been shared through inquiries, reviews and reports that were formed against the social work profession particularly over the past twenty years. Successive, systematic, critical commentaries were made that suggested the social work profession was failing, and that social workers were ill-equipped to carryout statutory duties in contemporary social work practice.

Within this study, the examination of literature is inclusive of a public Inquiry, reports and reviews that were commissioned as a direct response following the loss of two children's lives, Victoria Climbie and baby Peter. Consideration has been given to literature relating to the standards and ethics of social work, the challenges of successive regulatory frameworks that have been imposed on the profession and an outline of the new routes of entrance into the social work profession. The overall intention of the literature review and the qualitative primary research study to gain clarity on the social work profession and the expectations of the professional skill set of a qualifying social worker. I have explored the tensions identified that I consider compromised and subsequently impacted on the social work profession. The tensions relate to: the values and duties of the social work profession; the impact of successive government agendas since the 1970s in respect to the standards, regulations and expectations of statutory social work practice that have aimed to shape the professional skill set for the profession; the changes and impact of the educational routes into the profession and the relationship between the government, the social work profession and the imbalance of power.

The tensions related to both the substantial cuts to the funding of the services in which the social work profession is expected to carry out its duties and responsibilities and the questioning of qualifying and practicing social workers being deemed as "illequipped" with the necessary knowledge, skills and qualities to carry out their statutory duties. Therefore, I have argued the sequence of government interventions since the tragic loss of life of Victoria Climbie in 2000 failed to consider the political regime in which social work is practiced. As a consequence of the commentators of the commissioned reports and reviews failing to articulate the government responsibilities 
to the public and placing blame on the social work profession, I have argued that social workers and the social work profession are victims of epistemic, hermeneutical and testimonial injustice as a consequence of leaders failing to articulate the governments responsibilities to the public and placing blame on the social work profession.

\subsection{The tensions between the values and duties of the social work profession}

In respect to the values and duties of the social work profession, the conflicts identified between the opportunities to apply relationship-based practice and statutory duties have been explored. The dominance of applied statutory practice was considered to be as a result of the inadequate resources that had been afforded to the profession and this had impacted on relationship-based social work practice. The issue of defensive practice was found as a result of the actions and interventions that placed blame on the social work profession when a failure to protect children was found. This defensive approach was found to involve copious amounts of time-consuming paperwork to ensure accountability and that all aspects of duties and responsibilities are carried out. This time-consuming, powerful and fear-led process impacted on social workers not being able to afford the time to apply preventative methods of practice due to the need to respond to the high level of legal interventions required.

In terms of developments for the future, it would seem there has been a struggle to understand the values held within the social work profession and its greater intentions of value and relationship-based social work. The reduction and lack of appropriate funding to afford both longer term relationship based and statutory practices by the government has significantly impacted on the profession. It is difficult to consider how the embedded practices of carrying out legal duties can change in the foreseeable future in favour of applying relationship-based practice. To bring about change without funding ultimately forces the responsibility back onto the social work profession. Therefore, without any investment of funding to increase the workforce and the endorsement of the new routes of entrance into social work, the opportunities for social workers to practice within an organisation that promotes relationship-based practice, opposed to relentless duties of statutory interventions is unlikely. The importance of supporting social workers to consider models that promote a balance of working that enables the application of a professional skill set to embrace both relationship based practice and legal interventions is a move towards the currency of statutory social 
work. However, to overcome this, social workers need to be secure with the leadership and management that the elements of trust and taking risks are overcome in the future.

\subsection{The regulatory body and non-regulator body: the professional skill set}

The exploration into the professional skill set of social workers has involved considering the successive regulatory frameworks and the non-regulatory professionally funded organisation BASW, who both contribute to the informed standards and professional skill set of a social worker. When exploring the new routes of entrance into the social work profession, it was further highlighted that the KSS has also become integrated within statutory practice to inform firstly, the assessments of qualifying students who are entering into social work through the new educational routes into the profession and secondly, the postgraduates within the profession as a framework for the continuum of learning. It was found that the social work profession is operating within a number of assessment frameworks that has resulted in confusion and a lack of clarity and consistency for social workers in training and practice.

The possibility of clearly understanding what a professional skill set should look like in current practice has resulted in confusion due to so many contributions to its cause. What was found related to the distinct difference of current regulation when it is compared to the core competencies of CCETSW. The profession is once again in the process of change with SWE taking the lead in regulatory frameworks. Without any foreseen changes to the political agenda in the near future, the relationship-based model of working together between SWE and BASW will remain crucial to ensure the values and standards of the profession are not lost. They may benefit from looking back at CCETSW's simple model that trusted in the profession itself. In order to inform and shape the future of social workers the profession will benefit from one framework alone in order to prevent the confusion that currently exists.

\subsection{Educational routes into the profession}

The long established and new routes of social work education have been explored. The concerns that are expressed relate to: the reduction in time of education programmes; taught elements of the programmes to ensure a robust knowledge; the professional skill set is integrated within the learning of the student to prepare them for practice: the tension between a body of theoretical taught knowledge and skills was compared to work-based learning that informs practice knowledge. 
In terms of the future of social work education, it has been found that the government and local authorities are responding to the crisis that is relating to recruitment and retention in social work. It was considered this is being achieved through funding fast track routes of entrance into the profession which favour work-based learning although it is found the opportunity to hold a strong and generic knowledge base has been lost in favour of specialised and practice skills for qualifying social workers. However, with the findings of the study in terms of qualifying social work students' experiences of generic social work practice, it was found that the taught element on some of the generic programmes were dominated by teaching on children with the teaching on adults was considered poor with very little placement learning opportunities within the statutory sector and mental health available.

In terms of future developments, if the fast track routes are here to stay, it is a concern that the social work profession are then led into enforcing acts of hermeneutical epistemic injustice. This is due to the knower, being myself is aware that a greater depth and breadth of knowledge is required to operate as a social worker that has not been afforded or shared. Therefore, I would like to suggest that re-establishing ASYE programmes within local authorities will become crucial to the on-going learning needs of the social workers as a continuum of learning. Since the ASYE was heavily criticised by the majority of participants within this study it would benefit from an evaluation that was seen to be beyond the limitations of this study. This evaluation is to ensure the work is not repetitive and operate at a post graduate level to support a continuum of learning that is responsive to the values of the profession.

\subsection{Epistemic Injustice}

A key contribution to this study field is the application of Fricker's work on Epistemic Injustice to the social work profession. The decision to consider this theory was based on my concerns that social workers were being seen and verbally blamed as a failing profession and that this was an act of epistemic, testimonial and hermeneutical injustice. I have considered how the authors of the reports and reviews failed to share their knowledge of the wider issues of the profession and the consequences that impacted on the profession.

The importance of applying the lens of hermeneutical injustice enabled the exploration of the how the identity of the profession fell victim to prejudice referred to as a testimonial injustice. This view was borne from the systematic views shared of the 
authors of the aforementioned literature, who continually suggested social workers are ill-equipped to practice in statutory social work which was not the findings of the study. It was acknowledged that a diverse professional skill set was owned by a diverse group of people who become social workers who make up the social work profession.

It remains my view that a significant gap in the conscious knowledge of the commentators who have knowingly missed significant information that is referring to the funding of public services, could have changed the course of the investigations that took place. I suggest that should the political agenda have been considered, this could have changed the direction of the investigator's recommendations and therefore a more balanced and possible justifiable understanding in respect to the data and recommendations would exist and could have prevented the discriminatory views held against the profession.

\subsection{A future view of social work}

As a social worker and lecturer, I hold the view that a qualified social worker should start with a fundamental generic base of knowledge, skills and insight that relates to all areas of social work practice that is contributory to the notion of a continuum of learning. This view is reflective and conducive to the original standards and ethics articulated by IFSW and BASW. The overwhelming concerns that remain as a result of completing this study relate to the powerful and poorly informed influence of the government. The impact relates to the unreasonable expectations of the social work profession within the successive governments neo-liberal agenda's and the subsequent separation and division of the social work profession. The separation of services and dominance of statutory legal interventions within local authorities is at risk of diluting the value base, services and professional skill set of the profession and the identity of the profession as a whole system:

When I started this study, it was my view and intention to ensure a whole social work approach was adopted that was inclusive of adult and children services and promoted the fundamental value, respect and diversity I hold towards the professional skill base that operates within the profession. This view is held from a stance, that every social worker should have the opportunity to learn a generic professional skill set and engage in a continuum of learning throughout their profession which is respectful to the standards for registering to become a social worker. These standards and expectations allow all qualifying social workers to enter into the professing on an equal 
stance in any chosen route of the service they prefer. The importance of knowing that the commitment to a continuum of learning and becoming experts in the field of social work takes time which is based on the opportunities to practice and gain that strong professional skill set. As found within the data, it would seem there is an over credited view of the professional skill set of a qualifying social worker and it is therefore an unrealistic expectation for qualifying social workers to hold this level of expertise from the onset.

The challenge of remaining focused on generic social work practice while completing this study was due to: the separation within practice of adult, children and mental health services; the new routes of entrance into the profession specialising in their own areas of practice; the detail and attention of the government Inquiry, reports and reviews, apart from Moria Gibb's review that solely focused on children's services although all their recommendations can be seen to have impacted on the profession as a whole; the dominance of participation for this study, leaned heavily towards children services despite approaching both had adults and children services.

In respect to the overall findings of this study, the separation of services and the new educational routes of entrance into the profession are supporting the notion that a generic knowledge base isn't necessary in order to practice within the singular fields. I.e. children social workers do not need knowledge base of adults and adult social workers do not need a knowledge base of children's services. With the focus of the study relating to children services, this could suggest that adult services are not experiencing the same challenges as children. However, in terms of safeguarding and serious case reviews, the Winterbourne View Report (2014) and the recent Whorlton Hall case (2019) shared footage and evidence of horrific acts of abuse and psychological torture towards vulnerable adults whilst in the care of private and voluntary organising. Therefore, the knowledge and understanding of these issues and the impact of neo-liberalism within adult services was beyond the remit of this study but is undoubtedly worthy of its own study. The concerns for the future that are worthy of much greater consideration relate to: the impact on the values and ethics of the social work profession; neo-liberalism and its impact on adult social work practice; the dominance of attention of children services that has highlighted the lack of importance placed on the welfare of vulnerable adults; the rapidly forward movement of the governments agenda to privatise adult services. 


\section{References}

- Baoum-Fani Ntavelou, (2017) Theorizing Epistemic Injustice: Three Essays. Honours Thesis collection. 471. Wesley College Digital Scholarship and Archive

- Barth, R.P., Kolivoski, J.M., Lindsey, M., and Lee, B.R. (2013) 'Translating the Common Elements Approach: Social Work's Experiences in Education, Practice and Research, in Journal of Clinical Child and Adolescent Psychology, 43(2), pp.1-11

- BASW (2014) The Code of Ethics for Social Work. London: British Association of Social Workers (BASW)

- BASW (2018) Professional Capabilities Framework. London: British Association of Social Workers

- Beard, C., Wilson, J, P. (2013) Experiential Learning: A Handbook for Education, Training and Coaching. London: Kogan Page

- Beckett, C., and Maynard, A. (2005) Values and Ethics in Social Work: An Introduction. London: Sage

- Borque, L. B and Fielder, E. P. (2003) How to Conduct Self-Administered and Mail Surveys, 2nd edn. London: Sage

- Bourdieu, P. and Passerson, J.C. (1977) Reproduction in education, society and culture. Beverley Hills, CA: Sage

- Bourque, L.B., and Fielder, E.P. (2003) How to conduct telephone surveys, 2nd edn. London: Sage

- Bowe, R., Ball, S. J., and Gold, A. (1992) Reforming education and changing schools: Case Studies in policy sociology. London Routledge

- Braun, V. and Clarke, C. (2006) 'Using thematic analysis in psychology', Qualitative Research in Psychology, 3(2), pp. 77-101

- Burgess, H., and Taylor, I. (2005) Effective Learning and Teaching in Social Policy and Social Work. London: Routledge.

- Burgess, R. G. (1984) In the Field: An Introduction to Field Research. Crows Nest, Australia: Allen and Unwin

- Busher, H. (2002) Managing Change to Improve Learning, in The Principles and Practice of Educational Management.

- Busher, H. (2006) Understanding Educational Leadership: People, Power and Culture. Maidenhead: Open University Press

- Care Act 2014

- Care Standards Act 2000

- CCETSW (1991) Rules and requirements for the Diploma in Social Work, Paper 30, 2nd edn. London: Central Council for Education Training in Social Work

- Children Act 1989

- Children Act 2004

- Children Act 2015

- Children and Families Act 2014 
- Children and Families Directorate (2010) Role of the Registered Social Worker in Statutory Interventions: guidance for local authorities. [online] Available at: https://www.gov.scot/publications/role-registered-social-workerstatutory-interventions-guidance-local-authorities/pages/2/

- Clarke, J. (2004) Changing Welfare, Changing states: new directs in social policy. London: Sage

- Coady, D. "Two Concepts of Epistemic Injustice." Episteme 7.2 (2010): 10113. Web. - . "Epistemic Injustice." Forthcoming: Routledge Handbook of Epistemic Injustice (forthcoming)

- Creswell, J. W. (2014) Research Design: Qualitative, Quantitative and Mixed Methods Approaches. London: Sage

- Coady, D. (2010) 'Epistemic Injustice'

- Colins, J.A., and Fauser, B.C. (2005) 'Balancing the strengths of systematic and narrative reviews', in Human Reproduction Update, 11(2), pp. 103-104

- Creswell, J.W. (1998) Qualitative inquiry and research design: Choosing among five traditions. Thousand Oaks, CA: Sage

- Croisdale-Appleby, D. (2014) Re-visioning social work education: An independent review.

- Denscombe, M. (2014) The good research guide: for small-scale social research projects, 5th edn. Maidenhead: Open University Press.

- Department for Education (2009) Building a safe, confident future - the final report of the Social Work Task Force. London: The Stationery Office

- Department for Education (2011) Munro review of child protection: a childcentred system. London: The Stationery Office

- Department for Education (2014) Guidance: Apply for Step Up to Social Work. London: The Stationery Office

- Department for Education (2014) Knowledge and skills statement for child and family practitioners. London: The Stationery Office

- Department for Education (2014) Sir Martin Narey: overhauling children's social work training. London: The Stationery Office

- Department for Education (2015) Children's Social Work Workforce 2015. London: The Stationery Office

- Department for Education (2016) Independent evaluation of the Frontline Pilot: Research Report. London: The Stationery Office

- Department of Health (2015) Knowledge and Skills Statement for Social Workers in Adult Services. London: The Stationery Office

- Department of Health \& Social Care (2019) Chief Social Worker for Adult's annual report: 2018 to 2019 - social work leadership in changing times. [Online] Available at: https://www.gov.uk/government/publications/chief-socialworker-for-adults-annual-report-2018-to-2019/chief-social-worker-for-adultsannual-report-2018-to-2019-social-work-leadership-in-changing-times

- DeWalt, K. M., and DeWalt, B.R. (2011) Participant Observation: A Guide for Fieldworkers. London: Sage

- Doel, M. and Shardlow, S. (2005) Modern Social Work Practice: Teaching and Learning in Practice Settings. London: Routledge 
- Dominelli, L. (1988) Anti-oppressive practice in context. In H. McLaughlin (Eds) Understanding Social Work Research. London: Sage

- Douglas, M. (1994), Risk and Blame: Essays in Cultural Theory, London, Routledge

- European Convention of Human Rights 1998

- Fricker, M. (2007) Epistemic Injustice: Power and the Ethics of Knowing. Oxford: Oxford University Press

- Furseth, I., and Everett, E. (2013) Doing Your Master's Dissertation: From Start to Finish. London: Sage

- Gibbs, G. (1998) Learning by Doing: A guide to teaching and learning methods. Further Education Unit. Oxford: Oxford Polytechnic

- Giddens, A. (1991) Modernity and Self-Identity: Self and Society in the Late Modern Age. Stanford: Stanford University Press

- Giddens, A. and Sutton, P.W (2013) Sociology. Cambridge: Polity Press

- Glisson, C. and Hemmelgarn, A. L. (2018) Building Cultures and Climates for Effective Human Services: Understanding and Improving Organisational Social Contexts with the ARC Model. Oxford: Oxford University Press

- Grant, M.J., and Booth, A. (2009) 'A typology of reviews: an analysis of 14 review types and associated methodologies.' in Health Information and Libraries Journal, 26(2), pp. 91-108

- Gray, M., Midgley, J. and Webb, S.A. (2014) The SAGE Handbook of Social Work. London: Sage

- Green, J. (1997), Risk \& Misfortune, London, UCL Press.

- Greenfield, P. (2003) International Roots of Minority Child Development: Introduction to the Special Issue, in International Journal of Behavioural Development, 16(3).

- Habermas, J. (1966) Between Facts and Norms: Contributions to a Discourse Theory of Law and Democracy. in H. Busher (eds) Understanding Educational Leadership: People, Power and Culture. Maidenhead: Open University Press.

- Halton, C., Powell, F., and Scanlon, M. (2013) Continuing Professional Development in Social Work. Bristol: Policy Press

- HCPC (2014) Standards of conduct, performance and ethics. London: Health and Care Professions Council

- HCPC (2017) Standards of Proficiency. London: Health and Care Professions Council

- HCPC (2018) Standards of education and training guidance. London: Health and Care Professions Council

- Hemmelgarn, A. L. and Glisson, C. (2018) Building Cultures and Climates for Effective Human Services: Understanding and Improving Organisational Social Contexts with the ARC Model. Oxford: Oxford University Press.

- Hingley Jones, H., and Ruch, G. (2016) 'Stumbling through? Relationshipbased social work practice in austere times', in Journal of Social Work Practice. 30(3)

- Hockey, J. (1993) 'Research methods -- researching peers and familiar settings', in Research Papers in Education, 8(2), pp. 199-225 
- Hodgkinson, C. (1991) Educational Leadership: The Moral Art. Albany: SUNY Press

- Holloway, I. and Wheeler, S. (1996) Qualitative Research for Nurses. New Jersey, US: Wiley-Blackwell

- Hugman, R. (2010) Understanding International Social Work: A Critical Analysis. Basingstoke: Palgrave Macmillan.

- Hussein, S. (2011) Social Work Qualifications and Regulation in European Economic Area. London: General Social Care Council and Skills for Care and Development

- International Federation of Social Work available at https://www.ifsw.org/what-is-socialwork/global-definition-of-social-work/

- Jones, R. (2014) The Story of Baby P: Setting the Record Straight. Bristol: Policy Press

- Jones, R. (2015) 'The End Game: The marketisation and privatisation of children's social work and child protection', in Critical Social Policy, 35(4), pp.447-469

- Jones, R. (2017) 'Politicians are stealthily trying to take control of social work' in Guardian Professional Social Care Network

- Jones, R. (2017) 'The handling of the Children and Social Work Bill has been shambolic', in Community Care

- Kemshall, H. (2002) Risk, Social Policy and Welfare. Maidenhead: Open University Press

- Kemshall, H., Parton, N., Walsh, M. and Waterson, J. (1997) 'Concepts of Risk in Relation to Organizational Structure and Functioning within the Personal Social Services and Probation', Social Policy \& Administration 31(3): 213-32.

- Kolb, D. A. (2015) Experiential Learning: Experience as the Source of Learning and Development, 2nd edn. Harlow: Pearson

- Kruegar, R. A. (1988) Developing Questions for Focus Groups, KIT 3. London: Sage Publications LTD

- Krueger, R. A. (1998) Focus Group Interviewing. London: Sage

- Labaree, D. F. (2006) 'Mutual Subversion: A Short History of the Liberal and the Professional in Higher Education', in History of Education Quarterly. 46(1).

- Lishman, J. (2015) Handbook for Practice Learning in Social Work and Social Care: Knowledge and Theory, 3rd edn. London: Jessica Kingsley Publishers

- Lord Laming - Department for Children, Schools and Families (2009) The protection of children in England: a progress report. London: The Stationery Office

- Lord Laming (2003) The Victoria Climbie Inquiry: report of an inquiry by Lord Laming. London: The Stationery Office

- Major, D., Meakin, D., and Perrin, D. (2011) 'Building the capacity of higher education to deliver programmes of work-based learning', Higher Education, Skills and Work-Based Learning, 1(2), pp. 118-127 
- Martin, R. and Hollows, A. (2016) practising for social work practice: Integrating knowledge and skills for social work with children and families', Social Work Education. 35(5), pp. 576-588

- Mason, J. (2002) Qualitative Researching, 2nd edn. London: Sage

- May, T. (2001) Social Research. Maidenhead: Open University Press

- McLaughlin, H. (2012) Understanding Social Work Research, 2nd edn. London: Sage

- McLaughlin, K. (2007) 'Regulation and risk in social work: The General Social Care Council and the Social Care Register in Context', in British Journal of Social Work, 37(7), pp. 1263-1277

- McLaughlin, K. (2010) 'The Social Worker versus the General Social Care Council: An Analysis of Care Standards Tribunal Hearings and Decisions, in British Journal of Social Work, 40, pp. 311-327

- McLaughlin, K., Leigh, J., and Worsley, A. (2016) 'The State of Regulation in England: From the General Social Care Council to the Health and Care Professions Council', in British Journal of Social Work, 36(4), pp. 825-838

- McNicoll, A. (2016) Frontline to curb university influence on fast-track social work curriculum. Community Care. [online] available at:

https://www.communitycare.co.uk/2016/02/17/frontline-curb-universityinfluence-fast-track-social-work-curriculum/

- Milligan, L. (2014) 'Insider-outsider-inbetweener? Researcher positioning, participative methods and cross-cultural educational research', in Compare: $A$ journal of Comparative and International Education, 46(2), pp. 235-250

- Moustakas, C. (1994) Phenomenological research methods. In, John, W. Creswell (2014) Research Design: Qualitative, Quantitative and Mixed Methods Approaches. London: Sage

- O'Byrne, D. (2011) Sociological Theory. Harlow: Pearson.

- O'Connor, W. and Lewis, J. (1999) Experience of Social Exclusion in Scotland, Central Research Unit Report No. 73, Edinburgh: Scottish Executive.

- OFSTED (2017) Framework, evaluation criteria and inspector guidance for the inspection of local authority children's services. [online] Available at: https://assets.publishing.service.gov.uk/government/uploads/system/uploads/ attachment_data/file/793983/LACS_framework_and_evaluation_criteria120419.pdf

- Oliver, P. (2012) Succeeding with your literature review: a handbook for students. London: Open University Press

- Padgett, D. (2016) Qualitative Methods in Social Work Research, 3rd edn. London: Sage

- Parker, J., and Doel, M. (2013) Professional Social Work. London: Learning Matters | Sage Publications

- Patton, M.Q. (2002) 'Two Decades of Developments in Qualitative Inquiry: A personal Experiential Perspective', in Qualitative Social Work. 
- Perks, T., Orr, D., and Al-Omari, E. (2016) 'Classroom Re-design to Facilitate Student Learning: A Case Study of Changes to University Classroom', in Journal of the Scholarship of Teaching and Learning, 16(1), pp.53-68

- Polkinghorne, D.E. (1989) Phenomenological research methods. in R. Valle and S. Halling (eds) Existential phenomenological perspectives in psychology: Exploring the breadth experience, pp. 41-60. New York: Plenum

- Rawls, J. (1999) A theory of justice. Cambridge, MA: The Belknap Press of Harvard U Press

- Ritchie, J. and Lewis, J. (2003) Qualitative Research Practice: A Guide for Social Science Students and Researchers. London: Sage

- Robson, C. (2002) Real World Research: A Resource for Social Scientists and Practioner-researchers, 2nd edn. Oxford: Blackwell Publishers Ltd.

- Rose, N. (1996) 'The death of the social? Re-figuring the territory of government', Economy and Society, 25(3), pp. 327-356

- Ruch, G., Ward, A., and Turney, D. (2018) Relationship Based Practice: Getting to the heart of practice. London: Jessica Kingsley Publishing

- Ryan, F., Coughlan, M., and Cronin, P. (2009), 'Interviewing in qualitative research: The one-to-one interview', in International Journal of Therapy and Rehabilitation, 16(6), pp. 309-314

- Seden, J. (2011) Professional development in social work: complex issues in practice. London: Routledge

- Shaw, I. and Holland, S. (2014) Doing Qualitative Research in Social Work. London: Sage

- Skills for Care (2006) A Managers Guide to Developing Strategic Uses of National Occupational Standards. Skills for Care.

- Smith, J., and Noble, H. (2016) 'Reviewing the literature: choosing a review design', in Evidence Based Nursing. 21(2).

- Strauss, A. and Corbin, J. (1988) Basics of Qualitative Research: Grounded Theory Procedure and Techniques. 2nd edn. Thousand Oaks, CA: Sage.

- Strauss, A., and Corbin, J. (1998) Basics of Qualitative Research: Techniques and Procedures Developing Grounded Theory. Thousand Oaks: Sage Publications LTD

- Teddlie, C. and Tashakkori, A. (2009) Foundations of Mixed Methods Research: Integrating Quantitative and Qualitative Approaches in the Social and Behavioural Sciences. London: Sage

- The Children and Families Act 2014

- The Care Act 2014

- The Children Act 2015

- The Children and Social Work Bill 2017

- The European Convention of Human Rights 1998

- Thomas, J. (1995) Meaning in Interaction: An Introduction to Pragmatics. London: Longman

- Thompson, N. (2015) Understanding Social Work: Preparing for Practice. 4th edition. Basingstoke: Palgrave Macmillan 
- Trevithick, P. (2000) Social Work Skills: A Practice Handbook. Buckingham: Open University Press

- Trevithick, P. (2003) 'Effective relationship-based practice: A theoretical exploration', Journal of Social Work Practice. 17(2), pp.163-176

- Turner, A. (2019) Frontline drops compulsory master's from fast-track social work scheme. Community Care. [online] available at:

https://www.communitycare.co.uk/2019/02/15/frontline-drops-compulsorymasters-fast-track-social-work-scheme/

- Valle, R. S. and Halling, S. (1989) Existential-phenomenological perspectives in psychology: Exploring the breadth of human experience. New York, New York: Plenum Press.

- Waddell, J., and Vartuli, S. (2015) 'Moving from Traditional Teacher Education to a Field-Based Urban Teacher Education Program: One Program's Story of Reform. in The Professional Educator, 39(1).

- Warner, J. (2015) The Emotional Politics of Social Work and Child Protection. Bristol: Policy Press

- Wenger-Trayner, E. (2015) Learning in Landscapes of Practice: Boundaries, identity, and knowledgeability in practice-based learning. London: Routledge

- Working Together to Safeguard Children (2006) 


\section{Appendix One \\ Letter of Invitation to Participate in a Qualitative Study}

\section{Dear Colleagues}

I am a Senior Lecturer and the Academic Course Leader for Social Work for the University of Gloucestershire, I am also a registered Social Worker and Practice Educator for Social Work. I am conducting primary research and I would like to invite Social Workers who are completing or who have completed their ASYE - and who are in current practice within a statutory setting of either children and/or adult services the opportunity to participate in this research study. I am interested in speaking with all social workers who have qualified through the following routes: undergraduate/Masters/Step up/Frontline routes of entrance into the profession.

\section{Research Study}

The focus of my research is to explore the reflective views and experiences of qualified social workers and inquire if they feel they were adequately prepared to enter into the social work profession on completion of their selected taught route? Please find below some information to help you make an informed decision whether you would like to participate:

\section{The Motivation for this Study}

The intention is for the social workers to; reflect on their route of entrance into the profession and consider if they feel it equipped them with the necessary, knowledge, skills and qualities of expertise required to undertake the role and responsibilities they currently hold.

\section{Time and Location}

If you participate in this study you will be agreeing to engage in an individual, 1 hour (approximately), semi structured interview that, if agreed may be recorded or notes taken by myself as the sole researcher present. This interview can be completed either by telephone or face-to-face, depending on your preference. The interview will take place at an agreeable time with yourself during the months from March - Mid April 2019.

It is recommended that the face to face interview is to be conducted within one of the preferred University of Gloucestershire campuses and outside of your place of work in order to respect your anonymity and confidentiality. If you are agreeable to participating in this research activity please sign and return this form with your contact details directly to myself at the following email address [email redacted].

On receipt of your agreement I will be in contact with you to agree a preferred time and location for the interview to take place. Please also feel able to contact me if you have any queries that will help you to make an informed decision about your decision to participate. I would like to thank you in anticipation for taking the time to read and consider this invitation. I shall look forward to hearing from you in the very near future.

Kind Regards

Barbara Neale

Senior Lecturer/Academic Course Leader/Fellow in Higher Education - Pg/Masters in Social work

Research Participant

Name:

Email address

Telephone Number:

Please indicate whether you would prefer to undertake the interview face to face or by email:

Face to Face

Telephone 


\section{Appendix Two \\ Informed Consent and Participation Agreement}

\section{Consent for Participation for Interview research}

I volunteer to participate in a research project conducted by Mrs Barbara Neale- Senior Lecturer/Researcher University of Gloucestershire. I understand the project is designed to gather information about my own experiences, views and reflections in respect to the academic teaching and placement learning opportunities I completed to become a social worker and how that has informed my current practice and future career development. I understand I will be one of a minimum of possibly 12 people being interviewed and the themes identified through the findings will be shared with senior management and the academic learning programme in Gloucestershire.

My participation in this project is voluntary. I understand that I will not be paid for my participation. I may withdraw and discontinue participation at any time without penalty and up to four weeks following the interview. If I decline to participate or withdraw from the study, no one within my department will be told.

I understand that most interviewees will find the semi structured interviews interesting and thought provoking. If, however, I feel uncomfortable in any way during the interview session, I have the right to decline to answer any questions or to end the interview.

Participation involves being interviewed by Mrs Barbara Neale from the University of Gloucestershire. The interview will last approximately 1 hour. Notes will be taken during the interview. An audio tape of the interview and subsequent dialogue will be made. I can agree to not having the interview taped.

I understand that the researcher will not identify me or the team in which I work by name in any reports using information obtained from this interview, and that my confidentiality as a participant in this study will remain secure. Subsequent uses of records and data will be subject to standard data use policies which protect anonymity of individuals and institutions.

No staff from my organisation will be present at the interview nor have access to raw notes or transcripts. The precaution will prevent my individual comments from having any negative repercussions.

I understand that this research has been approved by the Ethics Committee University of Gloucestershire and the agreed County Council Ethics Review board. For research problems or questions regarding this project, the ethics committee may be contacted through information of the contact person at the Ethics Committee at University of Gloucestershire.

Should any information disclosed bring cause for concern in regard to safety and standards of practice, I understand this information will be shared with the named principal social worker agreed to lead on such matters for the purpose of this research within a confidential forum.

I have read and understand the explanation provided to me. I have had all my questions answered to my satisfaction and I voluntarily agree to participate in this study. 


\section{Participant Copy}

I understand there are two consent forms. One copy for the researcher and one copy for the participant. I have been given a copy of the consent form.

Participant:

Signature of Participant:

Date:

Participants Printed Name:

Researcher:

Signature of Researcher:

Date:

Researchers Printed Name:

\section{Researchers Copy}

I understand there are two consent forms. One copy for the researcher and one copy for the participant. I have been given a copy of the consent form.

Participant:

Signature of Participant:

Date:

Participants Printed Name:

Researcher:

Signature of Researcher:

Date:

Researchers Printed Name: 


\section{Appendix Three \\ De-briefing Form}

I would like to thank you very much for your support and engaging in this research activity. Please find below some information you may find helpful in respect to the research activity itself and future plans.

\section{Researcher: Barbara Neale}

Title of research - Social Work students are adequately prepared for statutory social work practice

\section{Aim of the Study}

The aim of this study is to gather the views and experiences of social workers on their route of entrance into the profession and their readiness to practice.

\section{Data Withdrawal}

Following the research activity, if you wish to have your data withdrawn please notify the researcher up to four weeks fooling the interview. If have any questions about the study or then please do feel able to contact the researcher at [email redacted] to discuss.

\section{Research Findings and Data Sharing}

The research findings may be presented to different organisations and in different forums to inform future practice development. As the researcher, I will not be able to contact you personally but your organisation will be informed of any plans to present the findings should it take place in the future.

\section{Personal Support}

If this study has raised personal issues that you are not comfortable discussing with the researcher, you are advised to contact the Principal @Social Worker for your Department who will be able to advise and support you.

\section{Complaints}

If you have concerns about this study, or the way in which it was conducted you are advised in the first instance to speak or email the researcher directly [email redacted]. You are also invited to contact the researcher's supervisor [email redacted]. If you feel your concerns have not been satisfactorily dealt with then please contact the chair of the University of Gloucestershire Ethics committee. [email redacted].

Thank you

Barbara Neale

Researcher 


\begin{abstract}
Appendix Four
Semi Structured Interview - Participant Number ...

Introductions - Research explanation - Aims of research:

The aim of my research is to explore the reflective views and experiences of qualified social workers and enquire if you feel you were adequately prepared to enter into the social work profession on completion of their selected taught route entrance into the profession.
\end{abstract}

The structure - The interview has five stages: Ethics, Demography, Transitions, Key Stage and Endings. I will be asking you to reflect on your views and experiences from becoming a qualified social worker and your developing practice since qualifying

The Focus - The key focus is to consider your view and experiences of the knowledge, skills and qualities required for social work. .

\title{
Stage 1 - Confirm Consent - Forms to be provided or sent \\ Confirm - participation - Confidentiality - Safeguarding \\ Confirm - I will be taking notes throughout the discussion - this is not audio recorded
}

\section{Stage 2 - Introductory details}

Name

Participant Number ...

Gender

DOB

\section{Ethnicity}

When did you complete your social work training?

Where did you complete your social work training?

Route of entrance - Masters

What qualifications did you need in order for you to undertake the social work training?

Did you move away to train or stay local to your home?

Assessment framework? The NOP's, PCF and SOP's

Have you completed your ASYE? Yes /No

Date

What is your current area of practice?

Is this the area of practice you intended when you qualified?

\section{Stage 3 - Transitions - ASYE}

What were the positives of completing your ASYE?

What were the challenges? 


\section{Stage 4 - Key Stage}

\subsection{Educational Routes}

What were the positives of your training that you feel prepared you for the work you are now undertaking?

What were the challenges of your training upon qualifying that you feel did not prepare you for the work you are now undertaking?

Placement

How many placements did you have during your training?

Where? SU group? Was this your choice?

Do you feel your taught programme could improve their model to ensure you are adequately equipped for the role you now hold? How? What?

\subsection{The Professional skill Set}

\section{Knowledge}

What type of knowledge and skills do you feel you gained whilst undertaking your teaching programme? What are your views on this now you are on practice?

Looking back what areas of knowledge do you feel are critical for a social worker to have on qualifying and entering into the profession?

\section{Skills}

What types of skills do you feel you gained whilst undertaking your teaching programme within the university? What are your views on this now you are on practice?

Looking back what types of skills do you feel are critical for a social worker to have on qualifying and entering into the profession?

\section{Qualities}

What types of qualities do you feel you gained whilst undertaking your teaching programme within the university? What are your views on this now you are on practice?

Looking back what types of qualities do you feel are critical for a social worker to have on qualifying and entering into the profession?

\section{Stage 5 - Ending}

What Next, what are your career aspirations? What is your future plan? 
Appendix Five

Demography

\begin{tabular}{|l|l|l|l|l|l|l|l|}
\hline $\begin{array}{l}\text { Case } \\
\text { Numb } \\
\text { er }\end{array}$ & $\begin{array}{l}\text { Gend } \\
\text { er }\end{array}$ & DOB & Ethnicity & $\begin{array}{l}\text { Year of } \\
\text { qualifyin } \\
\text { g }\end{array}$ & $\begin{array}{l}\text { Grades/Qualifi } \\
\text { cations on } \\
\text { entrance }\end{array}$ & $\begin{array}{l}\text { ASYE } \\
\text { completed }\end{array}$ & $\begin{array}{l}\text { Current area of } \\
\text { practice }\end{array}$ \\
\hline $\begin{array}{l}\text { Case } \\
1\end{array}$ & F & 1996 & $\begin{array}{l}\text { White } \\
\text { British }\end{array}$ & 2017 & $\begin{array}{l}\text { Access } \\
\text { Course }\end{array}$ & October 2018 & Adults \\
\hline $\begin{array}{l}\text { Case } \\
2\end{array}$ & F & 1988 & $\begin{array}{l}\text { White } \\
\text { British }\end{array}$ & 2016 & $\begin{array}{l}\text { Access } \\
\text { Course }\end{array}$ & October 2017 & $\begin{array}{l}\text { C\&F - child } \\
\text { protection }\end{array}$ \\
\hline $\begin{array}{l}\text { Case } \\
3\end{array}$ & F & 1989 & $\begin{array}{l}\text { Mixed } \\
\text { race }\end{array}$ & 2016 & $\begin{array}{l}\text { Access } \\
\text { Course }\end{array}$ & October 2017 & $\begin{array}{l}\text { Fostering/Disabilit } \\
\text { y C\&F }\end{array}$ \\
\hline $\begin{array}{l}\text { Case } \\
4\end{array}$ & F & 1970 & $\begin{array}{l}\text { White } \\
\text { British }\end{array}$ & 2017 & $\begin{array}{l}\text { 2.1 degree } \\
\text { and } \\
\text { experience }\end{array}$ & October 2018 & Adults \\
\hline $\begin{array}{l}\text { Case } \\
5\end{array}$ & F & 1986 & $\begin{array}{l}\text { White } \\
\text { British }\end{array}$ & 2016 & $\begin{array}{l}\text { Access } \\
\text { Course }\end{array}$ & White \\
British & 2015 & $\begin{array}{l}\text { Minimum } \\
\text { maths English } \\
- \text { access } \\
\text { course } \\
\text { distinction and } \\
2 \text { merits }\end{array}$ & July 2016 & $\begin{array}{l}\text { Supervising } \\
\text { social worker - } \\
\text { fostering C\&F }\end{array}$ \\
\hline
\end{tabular}




\begin{tabular}{|c|c|c|c|c|c|c|c|}
\hline $\begin{array}{l}\text { Case } \\
8\end{array}$ & $\mathrm{~F}$ & 1975 & $\begin{array}{l}\text { White } \\
\text { British }\end{array}$ & 2015 & Access & August 2016 & Safeguarding \\
\hline $\begin{array}{l}\text { Case } \\
9\end{array}$ & $\mathrm{~F}$ & 1982 & $\begin{array}{l}\text { White } \\
\text { British }\end{array}$ & 2015 & $\begin{array}{l}\text { Degree } 21 . \\
\text { But had a } 2.2 \\
\text { also had } \\
\text { English and } \\
\text { maths }\end{array}$ & 2016 & $\begin{array}{l}\text { Referral and } \\
\text { assessment - } \\
\text { Children in Need }\end{array}$ \\
\hline $\begin{array}{l}\text { Case } \\
10\end{array}$ & $\begin{array}{l}\text { No } \\
\text { furthe } \\
r \\
\text { action }\end{array}$ & & & & & & \\
\hline $\begin{array}{l}\text { Case } \\
11\end{array}$ & $\begin{array}{l}\text { No } \\
\text { furthe } \\
r \\
\text { action }\end{array}$ & & & & & & \\
\hline $\begin{array}{l}\text { Case } \\
12\end{array}$ & $\mathrm{~F}$ & 1980 & $\begin{array}{l}\text { White } \\
\text { British }\end{array}$ & 2016 & $\begin{array}{l}\text { I had a } 2.2 \\
\text { degree }\end{array}$ & 2017 & $\begin{array}{l}\text { Children - } \\
\text { safeguarding }\end{array}$ \\
\hline $\begin{array}{l}\text { Case } \\
13\end{array}$ & $\mathrm{~F}$ & 1988 & $\begin{array}{l}\text { Mixed - } \\
\text { white } \\
\text { black } \\
\text { African } \\
\text { Caribbea } \\
\mathrm{n}\end{array}$ & 2015 & A degree 2.2 & August 2016 & $\begin{array}{l}\text { Referral and } \\
\text { assessment C\&F }\end{array}$ \\
\hline $\begin{array}{l}\text { Case } \\
14\end{array}$ & $F$ & 1997 & $\begin{array}{l}\text { White } \\
\text { British }\end{array}$ & 2018 & 3 A levels & August 2019 & Safeguarding \\
\hline
\end{tabular}




\section{Stage Three- Transitions- ASYE}

\section{Appendix Six}

\begin{tabular}{|c|c|c|}
\hline $\begin{array}{l}\text { Positive Outcomes of } \\
\text { ASYE participation }\end{array}$ & Challenging Outcomes & $\begin{array}{l}\text { Impact on Social worker - } \\
\text { Collective Descriptive terms } \\
\text { used }\end{array}$ \\
\hline Protected caseloads & Expectations of the organisation & Hard work \\
\hline Specialised training & High levels of paperwork & emotionally demanding \\
\hline \multirow[t]{11}{*}{$\begin{array}{l}\text { work based learning } \\
\text { experience }\end{array}$} & $\begin{array}{l}\text { The confusion and time } \\
\text { consumption of cross } \\
\text { referencing of the PCF's SOP's } \\
\text { and KSS's assessment } \\
\text { framework. }\end{array}$ & Confusing \\
\hline & $\begin{array}{l}\text { ASYE was repetitive and not } \\
\text { progressive - teaching and } \\
\text { learning }\end{array}$ & Difficult \\
\hline & Poor leadership & Exhausting and time consuming \\
\hline & Poor support & Unreasonable amount of work \\
\hline & Poor guidance & Not feeling safe \\
\hline & Poor working relationships & $\begin{array}{l}\text { Fear of being held accountable for } \\
\text { poor practice }\end{array}$ \\
\hline & $\begin{array}{l}\text { Cross referencing of the } \\
\text { assessment frameworks }\end{array}$ & High levels of stress \\
\hline & $\begin{array}{l}\text { Unequal power imbalances } \\
\text { within the organisation }\end{array}$ & Concerns of neglectful practice \\
\hline & Reality versus idealism & $\begin{array}{l}\text { Disappointed to have to do the } \\
\text { ASYE }\end{array}$ \\
\hline & Supervision & \\
\hline & $\begin{array}{l}\text { Continuum of learning to } \\
\text { enhance the PSS }\end{array}$ & \\
\hline
\end{tabular}


Green $=$ Strong in supporting data - Amber $=$ varying experiences, some ambiguity - Red $=$ concerns

\begin{tabular}{|c|c|c|c|}
\hline $\begin{array}{l}\text { Organisational } \\
\text { expectations }\end{array}$ & Leadership & Work based learning & PSS \\
\hline Protected caseloads & Protected caseloads & Protected caseloads & Protected caseloads \\
\hline Specialised training & Specialised training & Specialised training & Specialised training \\
\hline $\begin{array}{l}\text { work based learning } \\
\text { experience }\end{array}$ & $\begin{array}{l}\text { work based learning } \\
\text { experience }\end{array}$ & $\begin{array}{l}\text { work based learning } \\
\text { experience }\end{array}$ & $\begin{array}{l}\text { work based learning } \\
\text { experience }\end{array}$ \\
\hline $\begin{array}{l}\text { Continuum of learning } \\
\text { to enhance the PSS }\end{array}$ & $\begin{array}{l}\text { Continuum of learning } \\
\text { to enhance the PSS }\end{array}$ & $\begin{array}{l}\text { Continuum of learning } \\
\text { to enhance the PSS }\end{array}$ & $\begin{array}{l}\text { Continuum of learning } \\
\text { to enhance the PSS }\end{array}$ \\
\hline \multirow{9}{*}{$\begin{array}{l}\text { Power imbalances } \\
\text { within the organisation }\end{array}$} & Supervision & Supervision & Supervision \\
\hline & $\begin{array}{l}\text { High levels of ASYE } \\
\text { paperwork }\end{array}$ & & \\
\hline & $\begin{array}{l}\text { The amount of } \\
\text { assessments } \\
\text { frameworks }\end{array}$ & & \\
\hline & $\begin{array}{l}\text { ASYE was repetitive } \\
\text { and not progressive - } \\
\text { teaching and learning }\end{array}$ & & \\
\hline & Poor leadership & & \\
\hline & Poor Support & & \\
\hline & Poor guidance & & \\
\hline & $\begin{array}{l}\text { Poor working } \\
\text { relationships }\end{array}$ & & \\
\hline & $\begin{array}{l}\text { unequal power } \\
\text { imbalances }\end{array}$ & & \\
\hline
\end{tabular}


Appendix Seven

Stage Four - Key Stage Knowledge, skills and Qualities - March - May 2019

\begin{tabular}{|c|c|c|}
\hline Taught Knowledge & Applied Knowledge & $\begin{array}{l}\text { Critical Knowledge, } \\
\text { Skills and Qualities at } \\
\text { point of Qualifying }\end{array}$ \\
\hline Marginalised people & Working with families & $\begin{array}{l}\text { To be a professional - } \\
\text { Understand professional } \\
\text { conduct and } \\
\text { expectations = } \\
\text { Professionalism }\end{array}$ \\
\hline Vulnerability & The legal process & $\begin{array}{l}\text { Working with people - } \\
\text { diverse families and } \\
\text { communities = Diversity }\end{array}$ \\
\hline Professional Practice & What safeguarding really is & $\begin{array}{l}\text { Service User centred } \\
\text { practice }=\text { Theories }\end{array}$ \\
\hline Professional identity & Analytical writing & $\begin{array}{l}\text { Being supported to } \\
\text { consider, apply and } \\
\text { adopt different } \\
\text { approaches = Theories }\end{array}$ \\
\hline Theories (undefined) & How to be professional & $\begin{array}{l}\text { Critical reflection of } \\
\text { practice = skills }\end{array}$ \\
\hline Methods (undefined) & $\begin{array}{l}\text { Understand good conduct - how to dress - } \\
\text { how to speak - how to behave }\end{array}$ & $\begin{array}{l}\text { Being able to challenge } \\
\text { and hold difficult } \\
\text { conversation = skills }\end{array}$ \\
\hline Law (undefined) & Carrying out and writing assessments & $\begin{array}{l}\text { To understand law }= \\
\text { Knowledge }\end{array}$ \\
\hline Risk (undefined) & Applying different approaches to cases & $\begin{array}{l}\text { Learning to be seen as } \\
\text { a continuum }\end{array}$ \\
\hline Strengths based practice & $\begin{array}{l}\text { Understand diversity - you have to } \\
\text { understand the people we work with, their } \\
\text { lives, their values, their religious base, their } \\
\text { stories. }\end{array}$ & Systems and processes \\
\hline Reflective skills & The reality of confidentially & $\begin{array}{l}\text { Political and sociological } \\
\text { knowledge }\end{array}$ \\
\hline Communication skills & Person centred practice & $\begin{array}{l}\text { Relationship based } \\
\text { practice }\end{array}$ \\
\hline \multirow[t]{5}{*}{$\begin{array}{l}\text { Learning to form your own } \\
\text { professional opinion. }\end{array}$} & $\begin{array}{l}\text { Managing change in teams and } \\
\text { organisations }\end{array}$ & $\begin{array}{l}\text { How to write } \\
\text { assessments - reports - } \\
\text { care plans - child } \\
\text { protection plans - } \\
\text { papers for court - we } \\
\text { were not prepared at all } \\
\text { for this. }\end{array}$ \\
\hline & $\begin{array}{l}\text { Managing and supporting feelings of } \\
\text { uncertainty }\end{array}$ & $\begin{array}{l}\text { Respecting other people } \\
\text { and professional } \\
\text { opinions = values }\end{array}$ \\
\hline & $\begin{array}{l}\text { Fostering and adoption - "This wasn't really } \\
\text { covered". }\end{array}$ & $\begin{array}{l}\text { A balance of knowledge } \\
\text { between adults and } \\
\text { children support and law } \\
=\end{array}$ \\
\hline & Systems theory & $\begin{array}{l}\text { Prioritising your work } \\
\text { according to risk and } \\
\text { deadlines }\end{array}$ \\
\hline & $\begin{array}{l}\text { Managing complex and challenging cases. } \\
\text { The casework is far more complex than } \\
\text { what universities prepared us for. }\end{array}$ & $\begin{array}{l}\text { Relationship based } \\
\text { practice }\end{array}$ \\
\hline
\end{tabular}




\begin{tabular}{|c|c|c|}
\hline & $\begin{array}{l}\text { Writing for social work - care plans, } \\
\text { assessments, safeguarding reports, police } \\
\text { reports, case reports. }\end{array}$ & $\begin{array}{l}\text { Analytical and recording } \\
\text { skills }\end{array}$ \\
\hline & $\begin{array}{l}\text { Gathering evidence - understanding what is } \\
\text { evidence }\end{array}$ & Thinking critically \\
\hline & People skills & Professional curiosity \\
\hline & Reality & $\begin{array}{l}\text { Communication at } \\
\text { every level and in lots of } \\
\text { ways. }\end{array}$ \\
\hline & Being a professional & $\begin{array}{l}\text { Understanding of } \\
\text { processes }\end{array}$ \\
\hline & Understanding Policies and procedures & $\begin{array}{l}\text { Different type of } \\
\text { assessments }\end{array}$ \\
\hline & Work load management & $\begin{array}{l}\text { Communication - } \\
\text { writing }\end{array}$ \\
\hline & & $\begin{array}{l}\text { Managing challenging } \\
\text { parents }\end{array}$ \\
\hline & & Courage \\
\hline & & Leadership \\
\hline & & $\begin{array}{l}\text { Management of } \\
\text { information }\end{array}$ \\
\hline & & $\begin{array}{l}\text { Concise, accurate } \\
\text { communication skills }\end{array}$ \\
\hline & & $\begin{array}{l}\text { Law - mental capacity - } \\
\text { we are dealing with } \\
\text { people's lives }\end{array}$ \\
\hline & & $\begin{array}{l}\text { Unconditional positive } \\
\text { regard and relationship } \\
\text { based practice }\end{array}$ \\
\hline & & $\begin{array}{l}\text { Telephone skills - we } \\
\text { are not taught how to do } \\
\text { this before going out into } \\
\text { placement. Having a } \\
\text { conversation in a room } \\
\text { full of people - social } \\
\text { workers do loads of } \\
\text { work over the phone but } \\
\text { you need to do this well } \\
\text { with a lot of people } \\
\text { around you. }\end{array}$ \\
\hline & & Sociology \\
\hline & & Restorative justice \\
\hline & & $\begin{array}{l}\text { The balance of sensitive } \\
\text { - assertive and calm }\end{array}$ \\
\hline & & Organisational skills \\
\hline & & Understanding risk \\
\hline & & How to safeguard \\
\hline & & $\begin{array}{l}\text { Making decisions and } \\
\text { being accountable for } \\
\text { them }\end{array}$ \\
\hline & & To apply law \\
\hline & & $\begin{array}{l}\text { Think about dignity and } \\
\text { respect }\end{array}$ \\
\hline
\end{tabular}




\begin{tabular}{l}
\hline Abstract themes - Notes \\
The placement team, the manager, the Practice educator to the success of practice learning and \\
the Placement supervisor were seen as critical. \\
\hline An observation = The difference between university taught and placement applied practice. \\
Participants were able to be much more descriptive of their responses to practice question rather \\
than academic taught modules. \\
All valued the generic programme who had completed one it was the challenge of the integration to \\
practice and the acceptance that theory was applied to practice with unconscious competence \\
most of the time. some struggled to integrate theory to practice. \\
\hline Different universities - One considered theirs to be "average academia" and two considered they \\
had received extremely poor academic levels of teaching and were dependent on the placements \\
to learn. \\
\hline All participants shared that teaching was predominantly children's services, adult areas were limited \\
and what was covered extremely poor. All participants expressed their level of dissatisfaction of the \\
teaching for adult services. One participant having to find some adult experience themselves as \\
part of their own learning which accumulated to six observation unmonitored days with no taught \\
element. \\
\hline Participants shared they had been influenced by their tutors to enter into children's services and \\
then maybe go into adult services when they are tired and have had enough. \\
A hierarchy of social work practice is also considered to be present amongst teams and \\
practitioners themselves. \\
\hline Generic based learning allows you to think broadly even when you don't realise you are doing it. A \\
lot of work is covered with adults in children's services as well but no emphasis. \\
\hline Less emphasis on lengthy assessments and more emphasis on practice. \\
\hline There should be much more time in placement. \\
\hline Generic teaching is important because of my understanding of adults, this helped me to understand \\
and support families fully. \\
\hline Watering down of teaching and learning in adult placements. \\
\hline
\end{tabular}

